\title{
๖Abyssal Heat Budget in the Southwest Pacific Basin
}

\author{
Ratnaksha Lele, ${ }^{\mathrm{a}}$ Sarah G. Purkey, ${ }^{\mathrm{a}}$ Jonathan D. NAsh, ${ }^{\mathrm{b}}$ Jennifer A. MacKinnon, ${ }^{\mathrm{a}}$

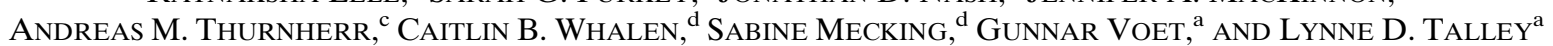 \\ ${ }^{a}$ Scripps Institution of Oceanography, University of California, San Diego, La Jolla, California \\ ${ }^{\mathrm{b}}$ College of Earth, Ocean, and Atmospheric Sciences, Oregon State University, Corvallis, Oregon \\ ${ }^{\mathrm{c}}$ Lamont-Doherty Earth Observatory, Columbia University, New York, New York \\ ${ }^{\mathrm{d}}$ Applied Physics Laboratory, University of Washington, Seattle, Washington
}

(Manuscript received 2 March 2021, in final form 2 September 2021)

\begin{abstract}
The abyssal southwest Pacific basin has warmed significantly between 1992 and 2017, consistent with warming along the bottom limb of the meridional overturning circulation seen throughout the global oceans. Here we present a framework for assessing the abyssal heat budget that includes the time-dependent unsteady effects of decadal warming and direct and indirect estimates of diapycnal mixing from microscale temperature measurements and finescale parameterizations. The unsteady terms estimated from the decadal warming rate are shown to be within a factor of 3 of the steady-state terms in the abyssal heat budget for the coldest portion of the water column and therefore cannot be ignored. We show that a reduction in the lateral heat flux for the coldest temperature classes compensated by an increase in warmer waters advected into the basin has important implications for the heat balance and diffusive heat fluxes in the basin. Vertical diffusive heat fluxes are estimated in different ways: using the newly available CTD-mounted microscale temperature measurements, a finescale strain parameterization, and a vertical kinetic energy parameterization from data along the P06 transect along $32.5^{\circ} \mathrm{S}$. The unsteady-state abyssal heat budget for the basin shows closure within error estimates, demonstrating that (i) unsteady terms have become consequential for the heat balance in the isotherms closest to the ocean bottom and (ii) direct and indirect estimates from full-depth GO-SHIP hydrographic transects averaged over similarly large spatial and temporal scales can capture the basin-averaged abyssal mixing needed to close the deep overturning circulation.
\end{abstract}

SIGNIFICANCE STATEMENT: The deep overturning circulation of the ocean is driven by northward flow of cold waters formed in the Southern Ocean and diffusion-driven upwelling from oceanic turbulence, both of which are difficult to measure and quantify accurately. This study aims to reconcile different methods of measuring the overturning in a large ocean basin by 1) inferring mixing required to sustain the overturning using long-term observations of inflow and outflow heat fluxes from a time-dependent heat budget and 2) direct/indirect observations of mixing within the basin. While our results show consistency of the basin-averaged mixing estimates from several different methods, this study also highlights the need to make sustained oceanic observations of mixing and circulation to further reduce uncertainty in the estimates.

KEYWORDS: Abyssal circulation; Diapycnal mixing; Mixing; Thermohaline circulation; In situ oceanic observations; Oceanic variability

\section{Introduction}

The meridional overturning circulation (MOC) regulates global climate through the exchange and distribution of heat, carbon, and nutrients throughout the global oceans (Meehl et al. 2006). The overturning structure and strength of the deep and bottom cells of the MOC are set by the balance between surface buoyancy loss at high latitudes that produces deep water, and diapycnal mixing throughout the global ocean driven by internal wave breaking and geothermal heating (Nikurashin and Ferrari 2013; Talley 2013; MacKinnon et al. 2017; Lumpkin and Speer 2007; Marshall and Speer 2012).

In the southwest Pacific (SWP) basin, the bottom limb of the MOC is fed by a mix of Antarctic Bottom Water (AABW),

¿ Denotes content that is immediately available upon publication as open access.

Corresponding author: Ratnaksha Lele, rlele@ucsd.edu originating primarily from the Antarctic continental shelf, and Lower Circumpolar Deep Water (LCDW), primarily made up of deep waters originating from the North Atlantic Ocean that have been modified in the Antarctic Circumpolar Current. The pathways of bottom water in the SWP basin have been relatively well observed, with this modified AABW mixture entering the SWP basin through an intensified deep western boundary current (DWBC) south of New Zealand that continues north along the Tonga-Kermadec Ridge (Reid 1997; Wijffels et al. 2001; Whitworth et al. 1999). The majority of the flow bottlenecks through the Samoan Passage before filling the entirety of deep North Pacific Ocean (e.g., Roemmich et al. 1996; Voet et al. 2016).

The inflow of cold deep water is largely balanced by vertical transfer of heat from above through diapycnal mixing. Direct observations of diapycnal mixing in the deep ocean are sparse in space and time, despite their critical importance in understanding large-scale ocean dynamics and closing the ocean heat budget (Waterhouse et al. 2014; MacKinnon et al. 2017). Observations from a pilot program to equip CTD rosettes used 
on decadally occupied Global Ocean Ship-based Hydrographic Investigations Program (GO-SHIP) repeat hydrographic sections with $\chi$-pods-self-contained instruments that measure temperature microstructure and package motion (see Nash et al. 2021, manuscript submitted to J. Atmos. Oceanic Technol.)_offer a new means for estimating deep-ocean mixing. Here we use these CTD $\chi$-pod data collected on the GO-SHIP hydrographic transect P06 to estimate the vertical heat transfer from turbulent mixing into the abyssal ocean.

When assessing the deep-ocean heat budget, it is important to note that the deep ocean is not currently in steady state but instead has been warming significantly in recent decades. Below $2000 \mathrm{~m}$, the global oceans have warmed at a rate equivalent to a downward heat flux of $0.065 \pm 0.040 \mathrm{~W} \mathrm{~m}^{-2}$ over the entire surface of Earth between the 1990s and 2000s, with the strongest warming rates found in the Southern Ocean closest to AABW formation sites (Purkey and Johnson 2010; Kouketsu et al. 2011; Desbruyères et al. 2016). This warming is likely being driven by a slowdown in $\mathrm{AABW}$ production and communicated globally on decadal time scales by deep planetary waves (Fukasawa et al. 2004; Kouketsu et al. 2009; Masuda et al. 2010; Purkey and Johnson 2012). In the SWP basin, the deep waters below $4000 \mathrm{~m}$ have warmed at a mean rate of $1.26 \pm 0.19^{\circ} \mathrm{mC} \mathrm{yr}^{-1}$ between the $1990 \mathrm{~s}$ and $2010 \mathrm{~s}$, with a possible stronger warming rate of $2.0^{\circ} \mathrm{mC} \mathrm{yr}^{-1}$ between the 2000s and 2010s (Purkey et al. 2019). Furthermore, the new Deep Argo array suggests an even larger warming rate of $3^{\circ} \mathrm{mC}$ $\mathrm{yr}^{-1}$ between 2014 and 2019 (Johnson et al. 2019).

Here, we present an in-depth analysis of the unsteady-state abyssal heat budget of the northern half of the SWP basin between 1992 and 2017 to assess our ability to directly measure all aspects of the local MOC. Using available ship-based hydrographic, mooring and Deep Argo data within the SWP basin (section 2), we quantify all terms in the heat budget of the abyssal ocean to test our current ability to directly monitor the processes controlling the MOC (section 3). Geostrophic velocity is calculated from four repeat hydrography sections along $32.5^{\circ} \mathrm{S}$ in the South Pacific and from velocity measurements in the Samoan Passage (Roemmich et al. 1996; Rudnick 1997; Voet et al. 2016) to estimate advective heat flux and compare it with new estimates of vertical heat flux from both microscale temperature measurements and finescale parameterizations of eddy diffusivity $\kappa$. In section 4 we compare results of the full unsteady-state heat budget, which accounts for the observed warming in the abyssal SWP basin, with a simple steady state heat budget calculation by ignoring the temporal variation that has previously been incorporated in various studies (e.g., Whitehead and Worthington 1982; Morris et al. 2001; Heywood et al. 2002). Last, in the framework of the abyssal heat budget, we discuss how changes in advective and diapycnal heat fluxes could drive abyssal warming by changing the MOC, and how well we can currently monitor and quantify each component (section 5).

\section{Data}

We use CTD, lowered acoustic Doppler current profiler (LADCP), and microscale temperature data collected during one or more of the four occupations of the zonal repeat hydrographic line P06 across the Pacific at $32.5^{\circ} \mathrm{S}$ (Fig. 1). The line was first occupied in 1992 as part of the World Ocean Circulation Experiment (WOCE) and was repeated in 2003, 2009, and 2017, first under the Climate Variability and Predictability (CLIVAR) program and later under GOSHIP. Stations sample from the surface to within $10-20 \mathrm{~m}$ of the ocean bottom or to 6000-m depth and are nominally spaced roughly every $55 \mathrm{~km}$ along the section, with closer spacing in regions of rough topography, trenches, and boundary currents.

All four occupations include 2-dbar-binned data for temperature $T$, salinity $S$, and pressure $P$ with accuracy to $0.002^{\circ} \mathrm{C}$, 0.002 PSS-78, and $3 \mathrm{dbar}$, respectively. Salinity data were calibrated to the International Association of the Physical Sciences of the Oceans (IAPSO) standard seawater, and any batch-to-batch offsets between standards were applied (Kawano et al. 2006). All temperature measurements were converted to the International Temperature Scale (ITS-90) and salinity is given in Practical Salinity Scale 1978 (PSS-78). potential temperature $\theta$ and neutral density $\gamma_{n}$ are calculated following Jackett and McDougall (1997).

LADCP data are available for the 2003, 2009, and 2017 occupations, but the 2003 and 2009 data are characterized by high noise as a result of only having a downward-looking $300-\mathrm{kHz}$ LADCP instrument, whereas the 2017 occupation had both an upward- and downward-looking LADCP. For this reason, only the LADCP data from the 2017 occupation are used for the finescale parameterization.

In addition, microstructure measurements of the dissipation rate of temperature variance $\chi$ were made along the 2017 occupation of the P06 section. Two $\chi$-pods, self-contained instruments that measure microscale temperature fluctuations using fast-response FP07 thermistors sampled at $100 \mathrm{~Hz}$ (Moum and Nash 2009), were mounted on the outer ring of the CTD rosette and extended above the top of the cage to avoid influence of the wake generated by the CTD package. Data were also collected from a downward-looking $\chi$-pod mounted near the CTD and LADCP head; however, measurements from this sensor were often contaminated (possibly by wake shed from the LADCP head) and so are not used here.

Eight months of full-depth CTD profiles collected from three Deep Argo floats (Fig. 1) deployed along the P06 line in 2017 at $168^{\circ} \mathrm{W}$ [float identifier (ID): 6030; WMO ID: 5902528], $160^{\circ} \mathrm{W}$ (float ID: 6031; WMO ID: 5902529), and $152^{\circ} \mathrm{W}$ (float ID: 6032; WMO ID: 5905161) are also used to assess temporal variability of the geostrophic flow over the abyssal plain. Each float took full-depth profiles every 10 days, sampling continuously in the upper 500 dbar and discretely every 250 dbar between 500 dbar and the bottom. As seen in Fig. 1, the floats considered in this study (Fig. 1, pink lines) stayed close to the initial deployment location along P06 over the course of the 8 -month period; hence, the measurement records are considered as stationary time series here. Also, time series of heat and volume transport through the Samoan Passage based on moored observations between 1992-94 (Rudnick 1997) and 2012-14 (Voet et al. 2016) are 


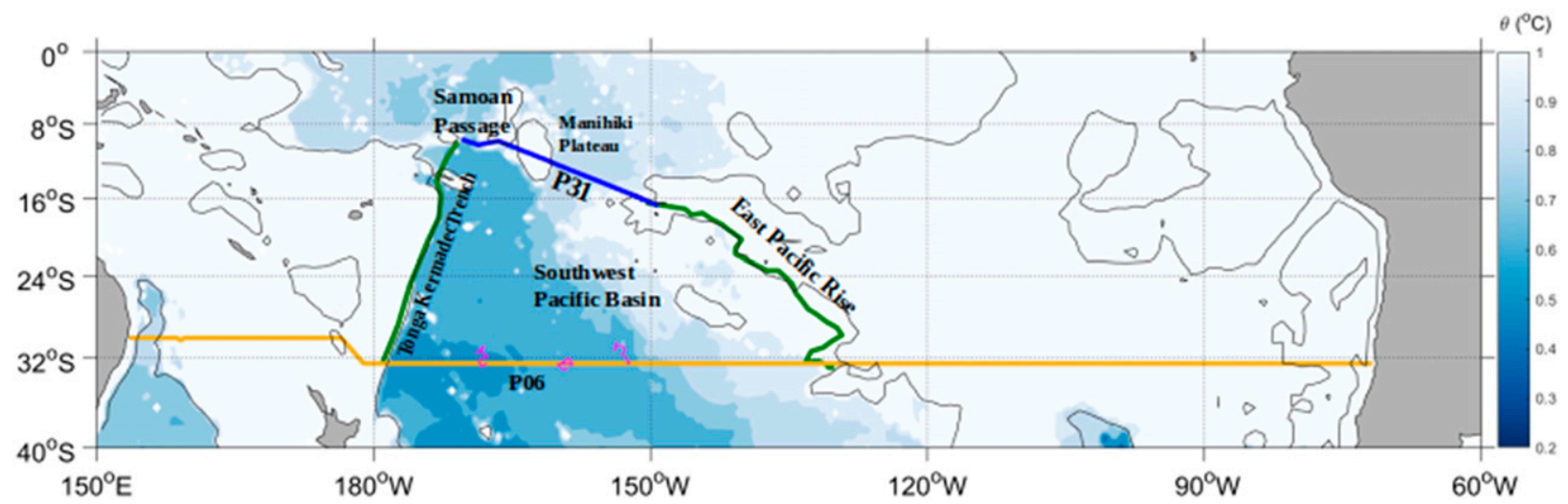

FIG. 1. Climatological bottom potential temperature (color shading; Gouretski and Koltermann 2004) within the study region of the northern southwest Pacific basin, defined by the 4000-m isobath (black contour) to the east and west (green), Samoan Passage and P31 to the north (blue), and P06 to the south (orange). Locations of three Deep Argo floats (pink) used to estimate geostrophic transport variability along across P06 in 2017-18 are indicated (section 3b).

used to estimate deep meridional outflow from the northern SWP basin.

\section{Methods}

We formulate a heat budget for the northern SWP basin. We distinguish the northern SWP basin from the rest of the SWP basin as the geographical region north of $32.5^{\circ} \mathrm{S}$. The cold waters considered here are isolated zonally by the Tonga-Kermadec Ridge along its western boundary and the east Pacific Rise along its eastern flank. The eastern and western sides of the deep basin are bounded by the 4000-m isobath running along the east Pacific Rise and Tonga-Kermadec Ridge, the northern edge bounded at $10^{\circ} \mathrm{S}$ by Samoan Passage and the P31 zonal hydrographic

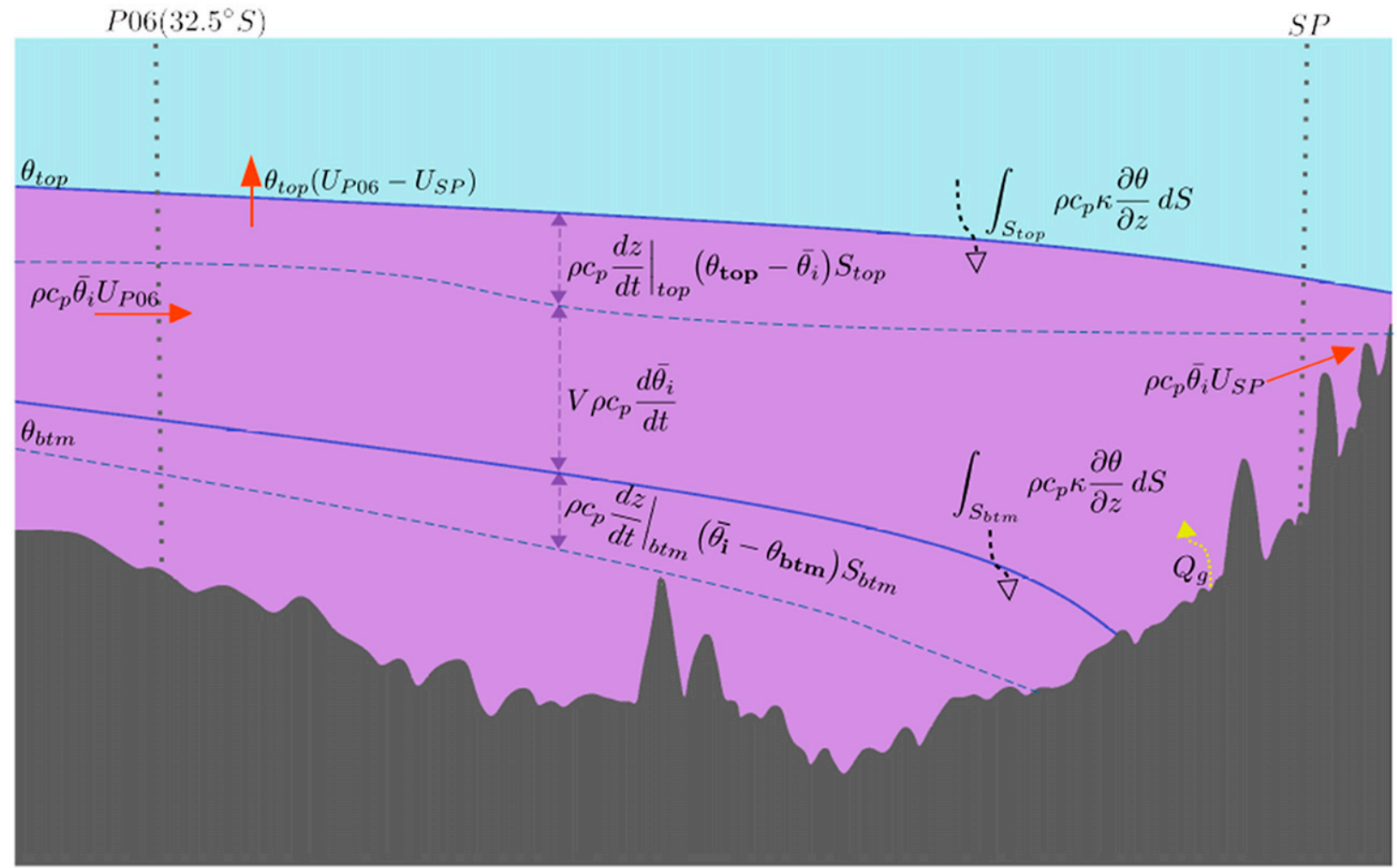

FIG. 2. Schematic of all terms in the heat budget as described by Eq. (8) showing heat fluxes in a zonal-mean isotherm framework (three unsteady terms, advective terms, and diffusive flux terms) associated with meridional flow entering through the P06 section at $32.5^{\circ} \mathrm{S}$ and exiting through the Samoan Passage (SP). 
section and southern end along the GO-SHIP P06 hydrographic section along $32.5^{\circ} \mathrm{S}$ (Fig. 1).

The unsteady-state abyssal heat budget expands on the framework in Morris et al. (2001) (Fig. 2). In this framework, the time rate of change of heat $Q$ and the divergence of advective heat fluxes into a defined volume are balanced by a diffusive heat flux and geothermal heating:

$$
\frac{\partial Q}{\partial t}+\nabla \cdot(Q \mathbf{u})=\nabla \cdot(\kappa \nabla Q),
$$

where $\mathbf{u}$ is the three-dimensional velocity field and $\kappa$ is the eddy diffusivity. The first term in Eq. (1), the unsteady term $\left(Q_{t}\right)$, is often neglected in abyssal heat budgets; however, we will show this term to be leading order in the coldest temperature classes (that are bounded by isotherms) and therefore include it here. This term represents the observed abyssal warming.

The heat budget calculation includes 41 isothermal layers (hereinafter, layers) $\left(0.6^{\circ}-1^{\circ} \mathrm{C}\right.$ in increments of $\left.0.01^{\circ} \mathrm{C}\right)$ within the deep basin. The spatial extent of each layer is defined by the climatological position of a top and bottom bounding isotherm from the $1^{\circ} \times 1^{\circ}$ WOCE hydrographic climatology (Gouretski and Koltermann 2004). First, the WOCE climatology potential temperature-pressure profiles are interpolated onto a fine $\left(0.01^{\circ} \mathrm{C}\right)$ isotherm grid between $0.6^{\circ}$ and $1^{\circ} \mathrm{C}$. The volume $V$ and top and bottom isotherm surface area $S_{\text {top }}$ and $S_{\text {btm }}$ of each layer can then be calculated by integrating spatially over the northern SWP basin. Note that the volume $V$ and top and bottom surface areas of each layer $i$ represent the "mean" volume and surface area of each of 41 layers over the climatological period of 1980-2004 (Gouretski and Koltermann 2004). While $V$ is constant in time, below we will introduce a $V^{\prime}$ term (defined as $d V / d t$ ) in the heat budget calculation reflecting the observed temporal changes in the volume of each layer in the basin (Fig. 2).

We integrate Eq. (1) over the layer volume $V$ and expand the terms by applying divergence theorem to get

$$
\begin{aligned}
\iiint_{V} \frac{\partial Q}{\partial t} d x d y d z+\oiint_{S}(Q \mathbf{u}) \cdot \hat{\mathbf{n}} d S= & \iint_{S_{\text {top }}} \kappa \frac{\partial Q}{\partial z} d S \\
& -\iint_{S_{\mathrm{btm}}} \kappa \frac{\partial Q}{\partial z} d S-Q_{g} .
\end{aligned}
$$

The last term in Eq. (2) is the geothermal heating term and is defined as $Q_{g}=Q_{o} \times \mathrm{FA} \times \mathrm{SA}$, a mean abyssal geothermal heat flux $\left(Q_{o} ; 0.05 \mathrm{~W} \mathrm{~m}^{-2}\right)$ times the fraction area (FA) of the total bottom bounding surface area (SA) of each defined layer in contact with the bottom. We then separate velocities in Eq. (2) into the vertical velocities $w$ and the horizontal inflow velocity along P06 $u_{P 06}$ and outflow velocity through Samoan Passage $u_{\text {sp: }}$

$$
\begin{aligned}
& \int_{V} \frac{\partial Q}{\partial t} d x d y d z+\left(\int_{S_{\text {south }}}-Q u_{\mathrm{P} 06} d S+\int_{S_{\text {north }}} Q u_{\mathrm{SP}} d S\right. \\
& \left.\quad+\int_{S_{\mathrm{top}}} Q W_{\mathrm{adv}} d S-\int_{S_{\mathrm{btm}}} Q W_{\mathrm{adv}} d S\right)=\int_{S_{\mathrm{top}}} \kappa \frac{\partial Q}{\partial z} d S \\
& \quad-\int_{S_{\mathrm{btm}}} \kappa \frac{\partial Q}{\partial z} d S-Q_{g} .
\end{aligned}
$$

Using Leibniz rule for the unsteady term in Eq. (3) whose integral bounds are changing in time, we can transform using

$$
\frac{d}{d t} \int_{z_{1}(t)}^{z_{2}(t)} Q(z, t) d z=Q\left(z_{2}, t\right) \frac{\partial z_{2}(t)}{\partial t}-Q\left(z_{1}, t\right) \frac{\partial z_{1}(t)}{\partial t}+\int_{z_{1}}^{z_{2}} \frac{\partial Q}{\partial t} d z
$$

where $z_{2}$ and $z_{1}$ are top and bottom bounds of the layer in the vertical direction. We use the transformation in Eq. (4) to split the unsteady term into three different terms and substitute into Eq. (3) to get

$$
\begin{aligned}
& \frac{d}{d t} \int_{V} Q d x d y d z-\int_{S_{\mathrm{top}}} Q\left(z_{2}, t\right) \frac{\partial z}{\partial t} d S+\int_{S_{\mathrm{btm}}} Q\left(z_{1}, t\right) \frac{\partial z}{\partial t} d S \\
& \quad+\left(\int_{S_{\text {south }}}-Q u_{\mathrm{P} 06} d S+\int_{S_{\text {north }}} Q u_{\mathrm{SP}} d S+\int_{S_{\mathrm{top}}} Q w_{\mathrm{adv}} d S\right. \\
& \left.\quad-\int_{S_{\mathrm{btm}}} Q w_{\mathrm{adv}} d S\right)+Q_{g}=\int_{S_{\mathrm{top}}} \kappa \frac{\partial Q}{\partial z} d S-\int_{S_{\mathrm{btm}}} \kappa \frac{\partial Q}{\partial z} d S
\end{aligned}
$$

Further, we replace heat $Q$ with $\rho c_{p} \bar{\theta}$ where $\rho, c_{p}$, and $\bar{\theta}$ are the density, heat capacity, and average potential temperature of the layer, respectively. Using mass conservation, we replace $W_{\mathrm{adv}_{\text {top }}}=\left(U_{\mathrm{P} 06}-U_{\mathrm{SP}}\right)_{i}$ and $W_{\mathrm{adv}_{\mathrm{btm}}}=\left(U_{\mathrm{P} 06}-U_{\mathrm{SP}}\right)_{i-1}$ corresponding to upward advection through the top and bottom isotherms, respectively, where $W$ and $U$ now represent volume transports instead of velocities. Further, on solving the integral in term 1 on the LHS of Eq. (5), it is transformed into the time derivative of the product of two functions that represent the average temperature and average volume of the layer, respectively, where the change in the volume is due to the movement of the top and bottom bounding isotherms of the layer, that is,

$$
\rho c_{p} \frac{d}{d t} \bar{\theta}(t) V(t)
$$

We use the product rule for derivatives to get

$$
\begin{aligned}
& V \rho c_{p} \frac{d \overline{\theta_{i}}}{d t}+\rho c_{p} \overline{\theta_{i}}\left(\left.\frac{d z}{d t}\right|_{\mathrm{top}} S_{\mathrm{top}}-\left.\frac{d z}{d t}\right|_{\mathrm{btm}} S_{\mathrm{btm}}\right)-\left.\rho c_{p} \theta_{\mathrm{top}} \frac{\partial z}{\partial t}\right|_{\mathrm{top}} S_{\mathrm{top}}+\left.\rho c_{p} \theta_{\mathrm{btm}} \frac{\partial z}{\partial t}\right|_{\mathrm{btm}} S_{\mathrm{btm}}-\rho c_{p} \overline{\theta_{i}} U_{\mathrm{P} 06} \\
& +\rho c_{p} \overline{\theta_{i}} U_{\mathrm{SP}}+\rho c_{p} \theta_{\mathrm{top}}\left(U_{\mathrm{P} 06}-U_{\mathrm{SP}}\right)_{i}-\rho c_{p} \theta_{\mathrm{btm}}\left(U_{\mathrm{P} 06}-U_{\mathrm{SP}}\right)_{i-1}+Q_{g}=\int_{S_{\mathrm{top}}} \rho c_{p} \kappa \frac{\partial \theta}{\partial z} d S-\int_{S_{\mathrm{btm}}} \rho c_{p} \kappa \frac{\partial \theta}{\partial z} d S .
\end{aligned}
$$

We split term 2 in Eq. (6) into two terms as follows: 


$$
\begin{aligned}
& V \rho c_{p} \frac{d \overline{\theta_{i}}}{d t}+\left.\rho c_{p} \frac{d z}{d t}\right|_{\mathrm{top}}\left(\overline{\theta_{i}}-\theta_{\mathrm{top}}\right) S_{\mathrm{top}}-\left.\rho c_{p} \frac{d z}{d t}\right|_{\mathrm{btm}}\left(\overline{\theta_{i}}-\theta_{\mathrm{btm}}\right) S_{\mathrm{btm}}-\rho c_{p} \overline{\theta_{i}} U_{\mathrm{P} 06}+\rho c_{p} \overline{\theta_{i}} U_{\mathrm{SP}}+\rho c_{p} \theta_{\mathrm{top}}\left(U_{\mathrm{P} 06}-U_{\mathrm{SP}}\right)_{i} \\
& -\rho c_{p} \theta_{\mathrm{btm}}\left(U_{\mathrm{P} 06}-U_{\mathrm{SP}}\right)_{i-1}+Q_{g}=\int_{S_{\mathrm{top}}} \rho c_{p} \kappa \frac{\partial \theta}{\partial z} d S-\int_{S_{\mathrm{btm}}} \rho c_{p} \kappa \frac{\partial \theta}{\partial z} d S .
\end{aligned}
$$

We rearrange the unsteady terms in Eq. (7) to get

$$
\begin{aligned}
& V \rho c_{p} \frac{d \overline{\theta_{i}}}{d t}-\left.\rho c_{p} \frac{d z}{d t}\right|_{\mathrm{top}}\left(\theta_{\mathrm{top}}-\overline{\theta_{i}}\right) S_{\mathrm{top}}-\left.\rho c_{p} \frac{d z}{d t}\right|_{\mathrm{btm}}\left(\overline{\theta_{i}}-\theta_{\mathrm{btm}}\right) S_{\mathrm{btm}}-\rho c_{p} \overline{\theta_{i}} U_{\mathrm{P} 06}+\rho c_{p} \overline{\theta_{i}} U_{\mathrm{SP}}+\rho c_{p} \theta_{\mathrm{top}}\left(U_{\mathrm{P} 06}-U_{\mathrm{SP}}\right)_{i} \\
& -\rho c_{p} \theta_{\mathrm{btm}}\left(U_{\mathrm{P} 06}-U_{\mathrm{SP}}\right)_{i-1}+Q_{g}=\int_{S_{\mathrm{top}}} \rho c_{p} \kappa \frac{\partial \theta}{\partial z} d S-\int_{S_{\mathrm{btm}}} \rho c_{p} \kappa \frac{\partial \theta}{\partial z} d S .
\end{aligned}
$$

Each term of the abyssal heat budget in Eq. (8) can now be evaluated within the northern SWP basin from observational data. From left to right, the first three terms are unsteady terms representing the energy needed to change the mean temperature within each layer [term 1: $\left.V \rho c_{p}\left(d \overline{\theta_{i}} / d t\right)\right]$ and the energy associated with increasing or decreasing the volume of water within each temperature class through the vertical heave of the upper or lower bounding isotherm [terms 2 and 3: $\left.\rho c_{p}(d z / d t)\right|_{\text {top }}\left(\theta_{\text {top }}-\overline{\theta_{i}}\right) S_{\text {top }}$ and $\left.\left.\rho c_{p}(d z / d t)\right|_{\mathrm{btm}}\left(\overline{\theta_{i}}-\theta_{\mathrm{btm}}\right) S_{\mathrm{btm}}\right]$. Terms 4-7 of Eq. (8) are simply the advective terms accounting for the loss or gain of energy through the horizontal inflow (term 4: $\rho c_{p} \overline{\theta_{i}} U_{\mathrm{P} 06}$; section 3b), horizontal outflow (term 5: $\rho c_{p} \overline{\theta_{i}} U_{\mathrm{SP}}$; section 3c), and vertical upwelling (terms 6 and 7), estimated using a combination of geostrophic flow from hydrography and Deep Argo floats and velocity data from moorings. The geothermal heating (term 8: $Q_{g}$; section 3e) is estimated assuming a constant heat flux proportional to the area of the isotherms in contact with the bottom across the abyssal plain. The sum of the left-hand side (LHS) terms is calculated as the inferred vertical diffusive heat flux (section 3f). Calculated as a residual, this term consists of diapycnal mixing processes as well as contributions from errors propagated from measurement error and other unresolved components in the LHS. We can then compare this term with vertical diffusive heat fluxes estimated using $\kappa$ derived from the strain-based parameterization (Gregg 1989; Whalen et al. 2012), a VKE-based parameterization (Thurnherr et al. 2015), and temperature microstructure measurements from $\chi$-pods (Moum and Nash 2009) (section $3 \mathrm{~g}$ ). Further partition of the right-hand side (RHS) term into a decomposition consisting of gradients of diffusivity, stratification and isotherm area as has been done in some recent studies (e.g., Drake et al. 2020; Spingys et al. 2021) is not considered here as it deviates from the scope of this study.

\section{a. Unsteady terms [Eq. (8), terms 1-3]}

The time derivatives in the unsteady terms $(d \bar{\theta} / d t$ and $d z / d t)$ are calculated using the linear trend in potential temperature, $\theta$, and isotherm height, $z$, using measurements from the four occupations of P06 following Purkey and Johnson (2012). The $\theta$-depth profiles from the four occupations are interpolated onto a regularly spaced vertical and horizontal grid. At each horizontal grid point along the section, the $\theta$-depth profile is also interpolated onto a regular spaced $\theta$ grid and the isotherm height is calculated as the distance above the bottom along the section. Then, a linear trend in $\theta$ and isotherm height versus occupation date are found at each horizontal and vertical grid point. The along-section average of $d \theta / d t$ along isobars and $d z / d t$ along isotherms is calculated and assumed to represent the basin mean [see Purkey and Johnson (2012) for more details].

\section{b. Horizontal heat transports across P06 [Eq. (8), term 4]}

The horizontal heat flux into the basin across P06 is calculated from the deep geostrophic volume transport estimated with corrected reference velocity from the LADCP (Hernández-Guerra and Talley 2016) and the observed hydrographic properties along the 4 occupations of the section. First, geostrophic velocity is estimated between station pairs along P06 using CTD data linearly interpolated on a 20-m depth grid assuming a level of no motion at $\gamma_{n}=28.1 \mathrm{~kg} \mathrm{~m}^{-3}$. In the South Pacific, $\gamma_{n}=28.1 \mathrm{~kg} \mathrm{~m}^{-3}$ roughly forms the boundary between southward gyre return flow of lighter intermediate and thermocline waters and northward transport of the denser AABW/LCDW (Ganachaud and Wunsch 2003).

A velocity correction for the level of no motion assumption at $\gamma_{n}=28.1 \mathrm{~kg} \mathrm{~m}^{-3}$ was applied based on LADCP data for stations between $179^{\circ}$ and $160^{\circ} \mathrm{W}$ in the deep western boundary current where the velocity is unlikely to be zero at $\gamma_{n}=$ $28.1 \mathrm{~kg} \mathrm{~m}^{-3}$ (Whitworth et al. 1999; Hernández-Guerra and Talley 2016). The correction was only applied to the 2003, 2009, and 2017 occupations of P06 owing to LADCP data availability. For each occupation, meridional LADCP velocities were linearly interpolated to the midpoint of station pairs and the mean and variance of the difference between the initial geostrophic velocity and LADCP velocity between depths of 2000 and $5500 \mathrm{~m}$ are calculated. The mean offset is applied to all station pairs where the variance is below $0.07 \mathrm{~cm}^{2} \mathrm{~s}^{-2}$. This variance cutoff corresponds to where the geostrophic and LADCP velocity profiles were determined to be vertically consistent across all depths through visual inspection of the profiles.

The net geostrophic transport below deep isotherms into the northern SWP basin across $32.5^{\circ} \mathrm{S}$ is calculated by integrating geostrophic velocities (Fig. 3) from west to east. To do this, the 

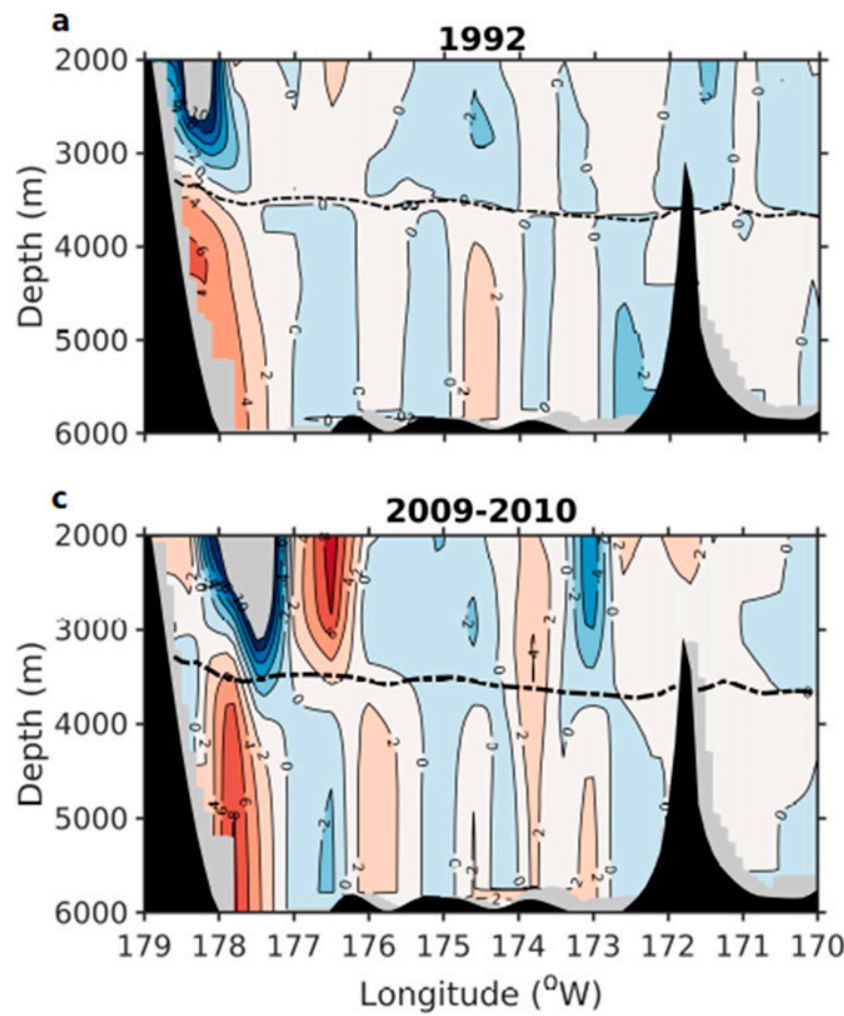

b

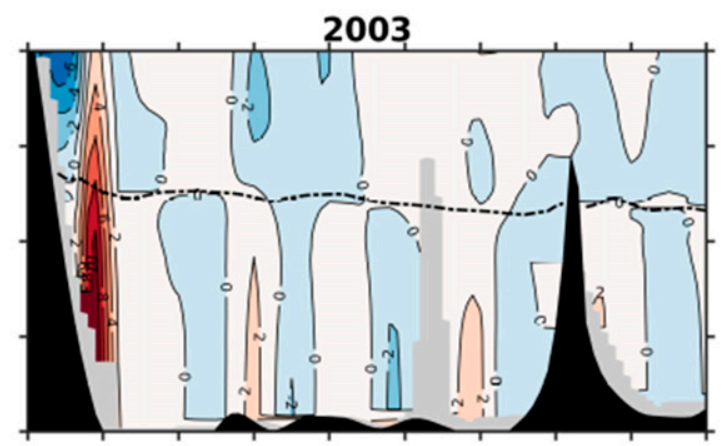

d

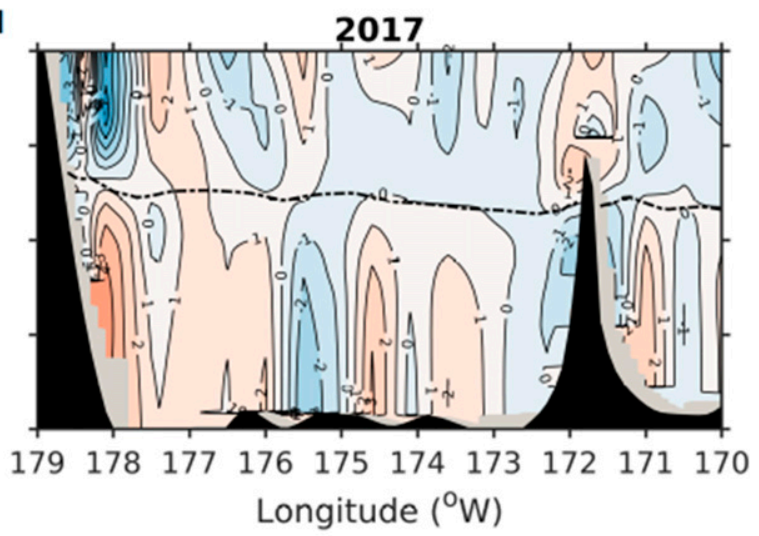

$$
\begin{array}{ccccccccccc}
\hline-10 & -8 & -6 & -4 & -2 & 0 & 2 & 4 & 6 & 8 & 10 \\
& & & & & \mathrm{~cm} / \mathrm{s} & & & & &
\end{array}
$$

FIG. 3. Meridional northward geostrophic velocities $\left(\mathrm{cm} \mathrm{s}^{-1}\right)$ referenced to LADCP [for (b)-(d)] across the deep western boundary current in the Tonga-Kermadec Ridge along P06 at 32.5 S in (a) 1992, (b) 2003, (c) 2009, and (d) 2017 with bottom bathymetry (black) and the mean depth of $\gamma_{n}=28.1 \mathrm{~kg} \mathrm{~m}^{-3}$ (dot-dashed black contour).

corrected geostrophic velocities are first linearly interpolated on to a regular potential temperature grid from $0.6^{\circ}$ up to $1^{\circ} \mathrm{C}$ in $0.01^{\circ} \mathrm{C}$ layers and linearly interpolated onto an evenly spaced $0.1^{\circ}$ longitude grid. Then, transport within each layer is integrated across the basin. The choice of the $1^{\circ} \mathrm{C}$ isotherm as the upper bound corresponds roughly to $\gamma_{n}=28.1 \mathrm{~kg} \mathrm{~m}^{-3}$, forming the boundary for the deep northward transport that flows through the Samoan Passage (e.g., Roemmich et al. 1996). For comparison, a similar calculation can be done by integrating the net transport below $\gamma_{n}=28.1 \mathrm{~kg} \mathrm{~m}^{-3}$ from the TongaKermadec Ridge to $130^{\circ} \mathrm{W}$ for each year (Fig. 4) of the P06 occupation. We use averaged mass transport estimates between 1992 and 2017 to estimate term 4 in Eq. (8) in the unsteady-state heat budget calculation.

To capture the variability in the integrated meridional transport across P06, we use guidance from previous estimates of mass transport variability in the Tonga-Kermadec Trench region between $178^{\circ}$ and $168^{\circ} \mathrm{W}$, as well as observed mass transport variability from two pairs of Deep Argo floats in the abyssal plain of the SWP basin east of $168^{\circ} \mathrm{W}$. Whitworth et al. (1999) estimated a DWBC transport variance of 59\% from the mean transport below $3200 \mathrm{~m}$ from a mooring time series in the Tonga-Kermadec Ridge region. Inverse model estimates from
Hernández-Guerra and Talley (2016) show transport variance in the DWBC below $\gamma_{n}=28.1$ between $25 \%$ and $48 \%$. Other studies also show a similarly wide range of basin integrated northward transport across the P06 section (Wijffels et al. 2001; Mazloff et al. 2010). Since transport variability on interannual and shorter time scales is largely unknown along the P06 section and has been shown to vary greatly in the DWBC from prior estimates, a factor of $50 \%$ of the net LADCP-referenced geostrophic transports is applied to account for temporal variability within each temperature bin for each year between $178^{\circ}$ and $168^{\circ} \mathrm{W}$ in the DWBC region.

For assessing temporal variability of transport east of $168^{\circ} \mathrm{W}$, the vertical profiles of temperature and salinity from three Deep Argo floats are interpolated vertically onto an evenly spaced 20 dbar vertical grid, and geostrophic transport between pairs of Deep Argo floats are calculated for pairs that surfaced within a week of each other for the period between October 2017 and June 2018. The temporal variance in the geostrophic transport over the 8-month time series is assumed to be representative of the expected variance over the full abyssal plain even though the floats did not fully cover the region. The geostrophic transport from the Deep Argo floats shows a $29 \%$ variation from the mean transport in the 8 -month 


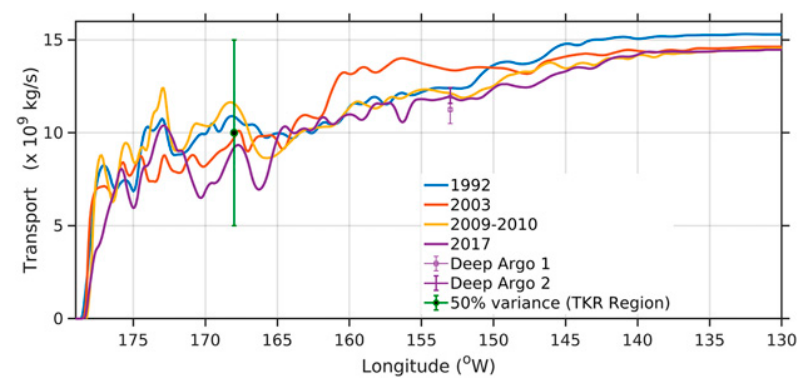

FIG. 4. Eastward integrated net northward mass transport $\left(\mathrm{kg} \mathrm{s}^{-1}\right.$ ) below $\gamma_{n}=28.1 \mathrm{~kg} \mathrm{~m}^{-3}$ along the four occupations of P06 (colors) between the Tonga-Kermadec Ridge $\left(179^{\circ} \mathrm{W}\right)$ and the east Pacific Rise $\left(130^{\circ} \mathrm{W}\right)$. Accumulated transport from all of the four occupations between $179^{\circ}$ and $168^{\circ} \mathrm{W}$ is shown with a green error bar representing $50 \%$ transport variance in the TKR region. Mean geostrophic transport with 1 standard deviation of the mean estimated between $\sim 168^{\circ}$ and $\sim 152^{\circ} \mathrm{W}$ (Deep Argo Float Pair 1) and $\sim 160^{\circ}$ and $\sim 152^{\circ} \mathrm{W}$ (Deep Argo Float Pair 2) from Deep Argo floats profiles collected between September 2017 and June 2018 is plotted at $152^{\circ} \mathrm{W}$, offset by the eastward integrated geostrophic transport in 2017 at $168^{\circ}$ and $160^{\circ} \mathrm{W}$, respectively, to show agreement with the hydrography line.

period. Therefore, we apply a $29 \%$ variance on the mean geostrophic flow in all temperature classes between $0.6^{\circ}$ and $1^{\circ} \mathrm{C}$ east of $168^{\circ} \mathrm{W}$ to account for the variation of geostrophic transport in the abyssal plain region.

The net meridionally integrated transports below $\gamma_{n}=$ $28.1 \mathrm{~kg} \mathrm{~m}^{-3}$ are within $1 \mathrm{~Sv}\left(1 \mathrm{~Sv} \equiv 10^{6} \mathrm{~m}^{3} \mathrm{~s}^{-1}\right)$ for the four P06 occupations as well as within error of previously published estimates for the region (Whitworth et al. 1999; Wijffels et al. 2001; Hernández-Guerra and Talley 2016). However, the application of transport time variances in the DWBC and the abyssal plain as a measure of the spread aims to account for potential differences in integrated transport resulting from choice of reference density level in calculating the geostrophic transport as well as other measurement errors and the overall variability in the circulation on mesoscale and longer time scale. We then consider this range of integrated mass transport to calculate horizontal heat transports in each isotherms between $0.6^{\circ}$ and $1^{\circ} \mathrm{C}$ in the heat budget calculation of the residual estimates of diffusivity (section 4 ).

\section{c. Horizontal heat transports across Samoan Passage [Eq. (8), term 5]}

To estimate heat fluxes out of the basin, the mean volume transport through the Samoan Passage is estimated using mooring data from 1992 to 1994 (Rudnick 1997) and 2012 to 2014 (Voet et al. 2016). No significant reduction in volume transport was observed between the two moored arrays but the volume of water within the coldest isotherms has changed (Voet et al. 2016). Therefore, here we use the 2012-14 mooring array heat outflow for the 2003, 2009, and 2017 budgets and the 1992-94 heat outflow for the 1992 budget. Outflow volume transports were interpolated onto the same regular potential temperature grid used for the inflow across P06. To account for northward flow around the Manihiki Plateau, an additional net transport of $2.7 \mathrm{~Sv}$ is distributed within temperature classes between $0.8^{\circ}$ and $1{ }^{\circ} \mathrm{C}$ and added to the budget calculation for all years following estimates from Roemmich et al. (1996). Our final estimates of diffusive heat fluxes and diffusivity for these temperature classes are not sensitive to this choice.

\section{d. Vertical advection [Eq. (8), terms 6 and 7]}

Upward advection, or upwelling, through the top bounding isotherm for each layer is calculated by solving for w through conservation of mass. To conserve mass within each layer beginning at the bottom-most isotherm $\left(0.6^{\circ} \mathrm{C}\right)$, the horizontal mass inflow and vertical advection through the bottom bounding isotherm has to be balanced by an equal horizontal outflow or vertical outflow through the top bounding isotherm, or a change in the layer volume.

\section{e. Geothermal heating [Eq. (8), term 8]}

The geothermal heating term is calculated as the product of the total surface area of the isotherm in contact with the bottom in the basin and a constant deep-ocean heat flux of $0.05 \mathrm{~W} \mathrm{~m}^{-2}$ (Hofmann and Maqueda 2009). We determine the total surface area of each layer in the temperature grid in contact with the ocean bottom using the $1^{\circ}$ latitude $\times 1^{\circ}$ longitude climatological maps of the ocean bottom temperature (Gouretski and Koltermann 2004)(Fig. 1). The time dependence of top and bottom surface areas $S_{\text {top }}$ and $S_{\text {btm }}$ on the geothermal heating term is not taken into account in the study since this term is orders-of-magnitude less than the other terms in Eq. (8) (see section 4) is ultimately negligible in comparison.

\section{f. Residual diffusive heat fluxes from basin heat budget [Eq. (8), LHS]}

A mean basin-averaged diffusivity $\kappa$ can be estimated from the diffusion term (Fig. 5a) by summing the LHS of Eq. (8). We estimate the basin-averaged diffusive heat flux and $\kappa$ on each isotherm by solving Eq. (8) using the surface area of bounding isotherm $S$ and vertical temperature gradient $\partial \theta / \partial z$ derived from WOCE-era hydrographic climatology (Gouretski and Koltermann 2004) (Fig. 6). Upper and lower bounds on the basinwide diffusivity estimates are made by propagating the transport temporal variability error of $50 \%$ (in the TongaKermadec Ridge region) and 29\% (in the abyssal plain) on mass flux along P06 and through the Samoan Passage for each layer in the heat budget (see section $3 b$ ).

\section{g. Diffusive heat fluxes from in situ measurements and parameterizations [Eq. (8), RHS]}

Vertical diffusive heat flux, turbulent dissipation rate $\epsilon$, and eddy diffusivity $\kappa$ for the basin are also estimated using a strain parameterization, a VKE-based parameterization, and temperature microstructure profiles from $\chi$-pods along P06.

\section{1) STRAIN-BASED FINESCALE PARAMETERIZATION}

Finescale parameterizations provide indirect means of estimating turbulent mixing in the ocean. Shear and strain-based parameterizations use internal wave-wave interaction theories to predict the downscale cascade of energy transfer from larger to smaller scales, resulting in turbulence production from 


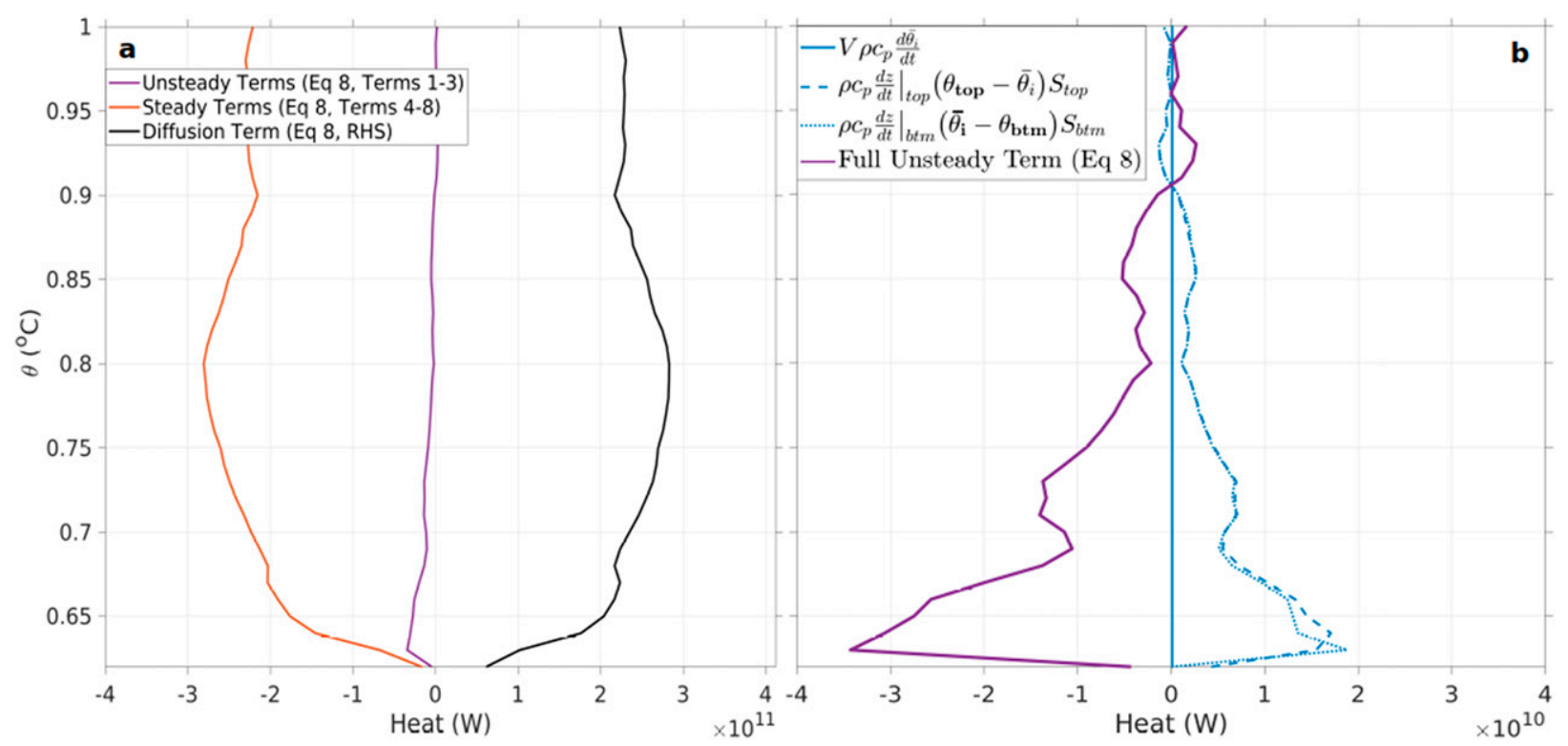

FIG. 5. (a) Heat balance for each layer between $0.6^{\circ}$ and $1^{\circ} \mathrm{C}(\mathrm{W})$ for the components of the heat budget in the SWP basin, which include unsteady terms [Eq. (8), terms 1-3], sum of the advective and geothermal heat terms, herein steady terms [Eq. (8), terms 4-8] and a diffusion term [Eq. (8), RHS] calculated using hydrographic data from the P06 section and mooring data in the Samoan Passage [Eq. (8)]. (b) Three components of the unsteady term (blue) as derived in Eq. (8) along with the total unsteady term (purple) calculated using isotherm heave $(d h / d t)$ (see Fig. 8b, below) and warming within the layer.

breaking internal waves (McComas and Müller 1981). Vertical profiles of strain variances are calculated along the P06 section using ship-based CTD data to estimate the rate of turbulent dissipation (Kunze et al. 2006; Whalen et al. 2012; Polzin et al. 2014) (Fig. 7a).

Strain variance $\left\langle\xi_{z}^{2}\right\rangle$ is calculated by integrating the buoyancynormalized spectra, starting integration at $\lambda=100 \mathrm{~m}$, which is constrained by the segment length $(200 \mathrm{~m})$ and avoids longer wavelength contamination by background stratification (Kunze et al. 2006), to between wavelengths of 10 and $40 \mathrm{~m}$, while also satisfying strain variance $\left\langle\xi_{z}^{2}\right\rangle<0.2$ to avoid underestimating the variance through oversaturation of the spectrum (Gargett 1990). We do not employ the use of shear measurements for the shearstrain parameterization (Kunze et al. 2006) in this study because of the unusually high noise levels in the deep-ocean shear measurements along this section. Therefore, we apply a constant ratio between shear and strain $R_{\omega}=3$ excluding the mixed layer [see Whalen et al. (2015) for details]. Profiles of $\varepsilon$ and $\kappa$ are calculated at each CTD station along the section from 200-m half-overlapping segments in depth. The parameterization gives average estimates of diffusivity and kinetic energy dissipation from breaking internal waves over multiple wave periods and does not account for mixing processes in the boundary layer, hydraulic jumps, double diffusion, or internal wave-driven turbulence in regimes with significant wave-mean flow interaction (Waterman et al. 2014).

\section{2) VERTICAL KINETIC ENERGY (VKE) PARAMETERIZATION}

In contrast to the shear and strain-based methods, the singleparameter VKE parameterization (Thurnherr et al. 2015) is based on an empirical relationship between dissipation of turbulent kinetic energy and the energy in high-frequency internal waves, which dominate vertical velocity in the interior ocean (e.g., Eriksen 1978). Requiring no input beyond vertical velocity, the VKE scaling between internal-wave energy and dissipation is not consistent with the latitudinal dependence of the shear/strain methods. From the relatively limited application to date, the VKE method does not seem to be affected by dataset-specific biases that exceed a factor of 2 that have been reported to affect some applications of the shear/strain method (Polzin et al. 2014; Thurnherr et al. 2015).

Using LADCP velocity data, the vertical fluid velocity $w$ is calculated following Thurnherr (2011) and Fourier transformed to obtain VKE spectra. The scaling between the VKE spectra and $\epsilon$ has been further described in the study by Thurnherr et al. (2015). Estimates of $\epsilon$ and $\kappa$, the latter based on the Osborn (1980) relationship $\kappa=\Gamma \epsilon / N^{2}$ with constant mixing efficiency $\Gamma=0.2$ (Gregg et al. 2018) and buoyancy frequency $N$ from CTD data, are calculated at each CTD station along the section and binned in 320-m half-overlapping segments vertically. Mean profiles and confidence intervals along P06 are computed in the same way as for the strain parameterization [see section $3 \mathrm{~g}(4)$ below; Fig. 7b].

\section{3) CTD-MOUNTED $\chi$-POD MEASUREMENTS}

High wavenumber temperature gradient fluctuations $d T^{\prime} / d z$ measured by the $\chi$-pods were obtained on each upcast and processed following the methods of Moum and Nash (2009) and Nash et al. (2021, manuscript submitted to J. Atmos. Oceanic Technol.) to compute the dissipation rate of the temperature variance $\chi$ : 

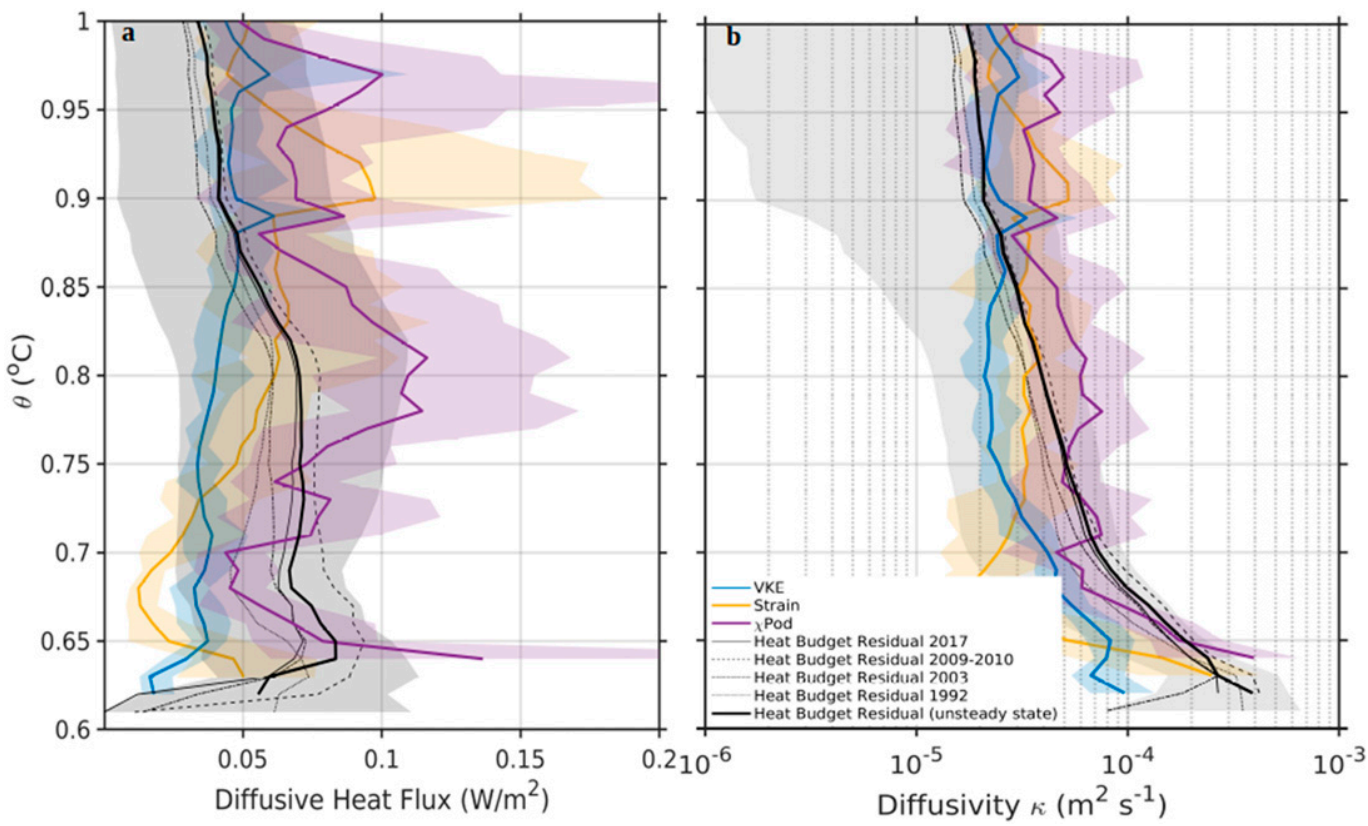

FIG. 6. (a) Profiles of basin mean diffusive heat flux $\left(\mathrm{W} \mathrm{m}^{-2}\right)$ calculated from the residual of a heat budget calculation of the northern SWP basin (black lines), also showing estimates resulting from 1 standard deviation of the meridional mass transport interannual variability along P06 (gray shading). Section-mean vertical profiles of diffusive heat flux calculated from two finescale parameterizations and a temperature microstructure along P06 are plotted (colored lines) with $95 \%$ bootstrapped confidence intervals (colored shading). (b) Profiles of diffusivity $\kappa\left(\mathrm{m}^{2} \mathrm{~s}^{-1}\right)$ for the northern SWP basin calculated from the heat budget-derived mean profiles of diffusive heat flux as plotted in (a) (black) with estimates resulting from 1 standard deviation of the meridional mass transport interannual variability along P06 (gray shading). Basin mean vertical profiles of $\kappa$ calculated from two finescale parameterizations and a temperature microstructure are plotted (colored lines) with $95 \%$ bootstrapped confidence intervals (colored shading).

$$
\chi=6 D_{T} \int_{0}^{\infty} \Psi_{T_{z}}(k) d k
$$

where $D_{T}$ is the thermal diffusivity and $\Psi_{T_{z}}$ is the wavenumber spectrum of temperature gradient fluctuations. In practice, $\Psi_{T_{z}}$ is not fully resolved by FP07 thermistor measurements, so assumptions must be made about the shape of the spectrum to compute $\chi$ at moderate TKE dissipation rates. While Goto et al. (2018) use a curve-fitting technique to determine $\chi$ from CTD-mounted sensors, this method requires that the spectral roll-off be resolved and is biased for $\epsilon>10^{-18} \mathrm{~W} \mathrm{~kg}^{-1}$. Instead we follow a procedure that is based on Moum and Nash (2009) that corrects for unresolved variance in 1-s-long spectra by simultaneously determining the $\epsilon$ and $\chi$ that are consistent with the resolved part of $\Psi_{T_{z}}$. Details of the method are provided in Nash et al. (2021, manuscript submitted to J. Atmos. Oceanic Technol.), who also outline a means for rejecting data contaminated by the CTD-rosette wake for profiles collected in moderate sea states and compare these estimates with those from a freefalling microstructure profiler to demonstrate that the method is not biased. Here we follow that method and use Osborn and Cox (1972) to calculate the eddy diffusivity of heat $\kappa_{T}$ :

$$
\kappa_{T}=\frac{\chi}{2(\overline{d T / d z})^{2}},
$$

where $\overline{d T / d z}$ is the mean background temperature gradient computed over $10-\mathrm{m}$ scales. The dissipation rate of kinetic energy is then calculated as

$$
\epsilon=\frac{N^{2} \chi}{2 \Gamma(\overline{d T / d z})^{2}},
$$

where $N^{2}$ is the squared buoyancy frequency and $\Gamma$ is the mixing efficiency, chosen to be a constant 0.2. Following Nash et al. (2021, manuscript submitted to J. Atmos. Oceanic Technol.), $\chi$ is computed in 1-s bins, data that are potentially contaminated by platform-induced noise are rejected, as are data in regions of very weak stratification where $\overline{d T / d z}$ is less than $10^{-4} \mathrm{~K} \mathrm{~m}^{-1}$. Retained data are binned into $200-\mathrm{m}$ halfoverlapping segments (Fig. 7c).

\section{4) BASIN MEAN DIFFUSIVITY PROFILES}

We calculate the basin mean diffusivity and $95 \%$ bootstrapped confidence intervals for each parameterization and $\chi$-pod measurements. First, parameterized estimates of diffusivity along the P06 section along isotherm surfaces are converted to diffusive heat fluxes by multiplying the diffusivity by the local vertical temperature gradient for a given isotherm $d \theta / d z$, density $\rho$, and specific heat $c_{p}$. We then take the mean along isotherms to determine the basin mean diffusive heat flux 

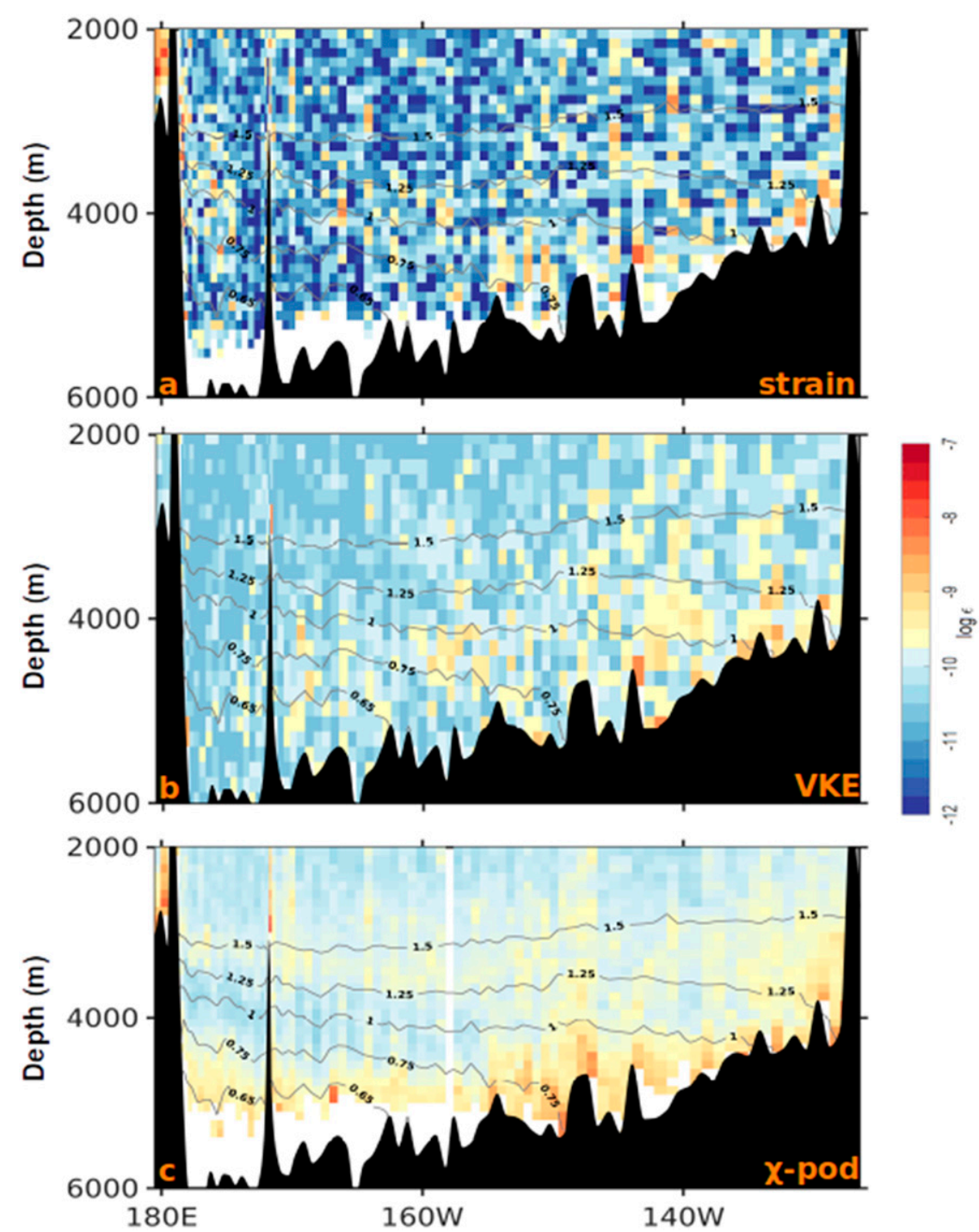

FIG. 7. Dissipation rate $\epsilon\left(\mathrm{W} \mathrm{kg}^{-1}\right)$ in the SWP basin along the 2017 occupation of the P06 section bounded in the east and west by the east Pacific Rise and Tonga Kermadec Ridge, respectively, with bottom bathymetry (black) from (a) a strain-only parameterization with a constant shear-to-strain ratio, (b) a VKE-based parameterization, and (c) temperature microstructure measurements of CTD-mounted $\chi$-pods along with the $0.65^{\circ}, 0.75^{\circ}, 1^{\circ}, 1.25^{\circ}, 1.5^{\circ} \mathrm{C}$ isotherms contoured as gray lines.

from each parameterization so as to compare it with the heat budget-derived diffusive heat fluxes (Fig. 6a). Further, we divide the above diffusive heat fluxes by the horizontal mean temperature gradient for each isotherm in the SWP basin determined from a hydrographic climatology to calculate the mean diffusivity for the basin (Gouretski and Koltermann 2004) (Fig. 6b).

\section{Results}

Each term in the heat budget in the northern SWP basin is examined using the measurements along P06 section and Samoan Passage and compared with diffusive heat flux and diffusivity estimates from finescale parameterizations and $\chi$-pod measurements. The occupations of P06 are also used to estimate the variability in the estimates of the diffusive heat flux from the heat budget owing to the variance in the geostrophic flow across P06, as well as the heat tendency term due to warming in the abyssal ocean [Eq. (8)].

\section{a. Unsteady-state terms}

The waters below $0.7^{\circ} \mathrm{C}$ have warmed significantly throughout the basin between the 1990s and 2010s and the coldest waters have disappeared, leading to more homogeneous bottom temperatures throughout the basin (Fig. 8; Purkey and Johnson 2010; Sloyan et al. 2013; Purkey et al. 2019; Johnson et al. 2019). 

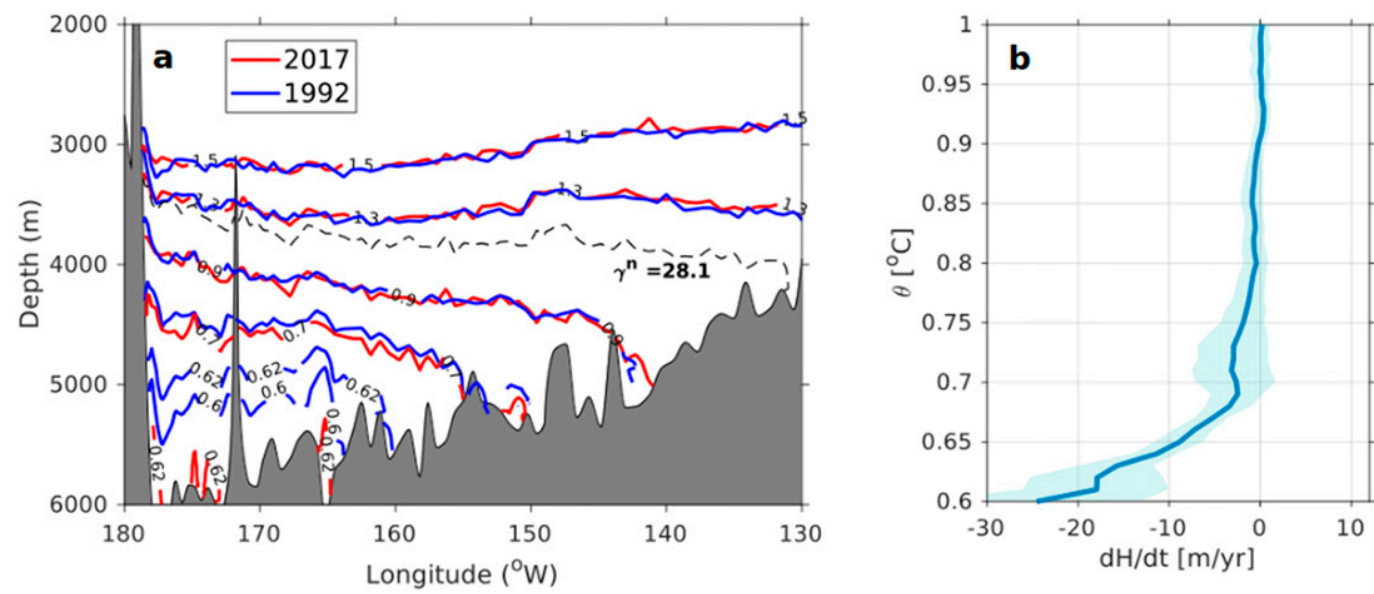

FIG. 8. (a) Isotherm contours in 1992 (blue) and 2017 (red) along P06 across the SWP basin with mean neutral density $\gamma_{n}=28.1 \mathrm{~kg} \mathrm{~m}^{-3}$ between 1992 and 2017 (dashed black line). (b) Rate of isotherm heave $d H / d t\left(\mathrm{~m} \mathrm{yr}^{-1}\right)$ calculated using four occupations of P06 between 1992 and 2017, along with 95\% confidence intervals (blue shading).

Observations along P06 between 1992 and 2017 show the rate at which the deepest isotherms have fallen in the coldest layers $\left(\sim 25 \mathrm{~m} \mathrm{yr}^{-1}\right.$ at $\left.0.6^{\circ} \mathrm{C}\right)$, which results in a substantial loss in volume of cold water (Fig. 8b).

In Eq. (8), this warming is included in the heat budget through three terms. The first term is the unsteady warming term $V \rho c_{p}\left(d \overline{\theta_{i}} / d t\right)$, which accounts for increase in heat content of the layer over time. This term depends on the grid spacing and accounts for the fact that discrete isotherm bins could experience nonuniform warming that results in changing the mean temperature $\overline{\theta_{i}}$ of the water within that bin. Since our isotherm bins are very fine $\left(0.01^{\circ} \mathrm{C}\right)$, this term is smaller than the other unsteady terms in our framework (Fig. 5b).

Second, the effect of deep warming is accounted for in Eq. (8) through the rate of change in isotherm volume in the terms

$$
\begin{gathered}
\left.\rho c_{p} \frac{d z}{d t}\right|_{\mathrm{top}}\left(\theta_{\mathrm{top}}-\overline{\theta_{i}}\right) S_{\mathrm{top}} \quad \text { and } \\
\left.\rho c_{p} \frac{d z}{d t}\right|_{\mathrm{btm}}\left(\overline{\theta_{i}}-\theta_{\mathrm{btm}}\right) S_{\mathrm{btm}}
\end{gathered}
$$

and represents a basinwide contraction or expansion of the volume of a given isotherm and the energy required to warm a given volume of water from a given isotherm by $0.01^{\circ} \mathrm{C}$ to move it into the warmer layer. This effect is roughly similar for the top and bottom bounding isotherms throughout much of the deep ocean and accounts for the bulk of the warming tendency term (Fig. 5b, purple). Consequently, the heat tendency term reduces to near-zero as the basinwide isotherm contraction goes to zero, representing a steady-state in the warmer isotherm classes above $0.85^{\circ} \mathrm{C}$.

We have assumed for our calculation that the rate of isotherm heave in the basin observed along P06 (Fig. 8b) is representative of the meridional variation in the entire basin. This is supported by data from GO-SHIP lines P15 and P16, the two meridional sections along the east and west sides of our study region, showing similar rates since the 1990s (see Purkey et al. 2019).

\section{b. Lateral transport from geostrophic velocities}

The structure and magnitude of geostrophic velocity across P06 into the northern SWP basin is consistent between occupations, with small differences in magnitude and location of the DWBC (Fig. 3). We find the highest velocities in the DWBC to occur within the core of the DWBC with mean velocities between 3 and $10 \mathrm{~cm} \mathrm{~s}^{-1}$ found below $4000 \mathrm{~m}$ between $179^{\circ}$ and $177^{\circ} \mathrm{W}$. However, structure and location of the DWBC core vary between occupations. Despite this spatial variability within the DWBC, the integrated northward mass transport across the northern SWP basin in the four occupations is remarkably similar below $\gamma_{n}=28.1 \mathrm{~kg} \mathrm{~m}^{-3}$ with net transport ranging from $14.6 \times 10^{9} \mathrm{~kg} \mathrm{~s}^{-1}$ to $15.3 \times 10^{9} \mathrm{~kg} \mathrm{~s}^{-1}$ (Fig. 4). In all four occupations, over half of the total transport is found east of $178^{\circ} \mathrm{W}$ within the DWBC. Some southward recirculation is observed to the west adjacent to the DWBC, but overall northward transport is observed between $170^{\circ}$ and $140^{\circ} \mathrm{W}$, until the cumulative sum of the transport becomes constant around $130^{\circ} \mathrm{W}$, where the $\gamma_{n}=$ $28.1 \mathrm{~kg} \mathrm{~m}^{-3}$ isopycnal "bottoms out" along the east side of the basin.

Despite the total northward volume transport staying relatively constant across the four occupations of P06 (Fig. 4), the temperature of the northward-flowing waters changed substantially between occupations. The coldest waters found along $32.5^{\circ} \mathrm{S}$ within the northern SWP basin warmed from $0.6^{\circ} \mathrm{C}$ in 1992 to $0.62^{\circ} \mathrm{C}$ in 2017 (Fig. 8).

\section{c. Residual diffusivity from heat budget}

Summing the left-hand side of Eq. (8) gives the vertical diffusion term needed to close the budget (Fig. 5a, black). We find that the inferred diffusive heat fluxes below $0.7^{\circ} \mathrm{C}$ increased by around a factor of 3 relative to the steady state diffusive fluxes with the inclusion of the unsteady terms in 
Eq. (8) that are leading order in the coldest part of the water column (below $0.7^{\circ} \mathrm{C}$ ).

A reduction in the cross-isotherm upwelling term (not shown) occurs mainly below the $0.75^{\circ} \mathrm{C}$ isotherm because of the reduction in volume and heat transport in the coldest layers, which is indicated by an isotherm heave signal $d h / d t$ along the P06 section (Fig. 8b). Consequently, this reduction in crossisotherm upwelling is compensated through an increase in the diffusion term in those isotherm classes (Fig. 5a, black). This difference in decreased upwelling transport and increased downward diffusion is most prominent below $0.65^{\circ} \mathrm{C}$ where the bulk of the warming is concentrated; the contribution of the unsteady terms (Fig. 5a, purple) is nonnegligible in the threeterm balance between steady, unsteady and diffusion terms. The contribution of the unsteady terms to the increased diffusive heat flux reduces greatly by $0.75^{\circ} \mathrm{C}$ and is virtually the same as would be under a steady-state assumption above $0.8^{\circ} \mathrm{C}$. This is primarily driven by a gradual minimization of the warming-driven isotherm heave signal of waters with temperatures greater than $0.75^{\circ} \mathrm{C}$ (Fig. 8b), as shown by persistent isotherm positions along P06 between 1992 and 2017 (Fig. 8a). The unsteady state diffusive heat flux and diffusivity estimates from the heat budget calculation and the associated uncertainties calculated using the full range of northward heat transport in the SWP basin (see sections $3 b$ and $3 c$ ) lie within the uncertainty estimates from the finescale VKE and strain parameterizations as well as $\chi$ pod observations for most of the temperature classes considered in the budget.

\section{1) STEAdy-STATE MODifiCATION OF THE HEAT BUDGET}

In addition to formulating the full unsteady-state budget [Eq. (8)], we consider the effect of neglecting the unsteadystate terms to incorporate the more widely used framework of a steady-state heat budget (Whitehead and Worthington 1982; Hogg et al. 1982; Polzin et al. 1997; Morris et al. 2001; Heywood et al. 2002). Here we assume zero heat accumulation within each layer and do not consider the unsteady terms in Eq. (8). That is, the heat budget is a balance between only the horizontal advection calculated using mass and heat transport estimates from individual occupations of the P06 section, vertical upwelling, geothermal heating, and diapycnal diffusion (Fig. 2). To conserve heat within a layer, heat entering within a layer must either exit the layer as outflow, upwell by advection or mix through vertical diffusion. Similar to the unsteady-state heat budget, the diffusive heat flux is in balance with the advective heat flux without the presence of the unsteady terms.

Despite the diffusive heat term being the same order of magnitude as the advective terms as well as being notably lesser in magnitude from the unsteady-state-derived estimates of diffusive heat flux in the coldest isotherms below $0.65^{\circ} \mathrm{C}$ (Fig. 6a), the inferred diffusivity remains well within the error of the unsteady-state estimate accounting for interannual variations in the advective transport (Fig. 6, gray shading). The inferred diffusivity profile from both unsteady-state and steady state heat budgets (Fig. 6b) show enhancement of turbulent mixing near the bottom, in line with recent results showing elevated levels of turbulent mixing occurring near bottom topography (up to $\sim 10^{-3} \mathrm{~m}^{2} \mathrm{~s}^{-1}$ here) in the abyssal basins driven in-part by internal wave interaction with ocean topography (e.g., Polzin et al. 1997; Ledwell et al. 2000; Waterhouse et al. 2014; Mashayek et al. 2017; Drake et al. 2020). Our results also show that variations up to a factor of $8-10$ between steady and unsteady budget estimates are possible when considering the full range of uncertainty bounds that account for variability in lateral heat transport in the basin.

\section{d. Diffusivity $\kappa$ and dissipation rate $\epsilon$ from finescale parameterizations and $\chi$-pods}

In much of the SWP basin's interior and in regions away from surface and near-bottom influences, dissipation rates are relatively weak, as measured by $\chi$-pod observations and finescale parameterizations (Fig. 7). However, regions of intensified mixing are observed along the interface between the $1^{\circ}$ and $1.25^{\circ} \mathrm{C}$ isotherms that roughly forms the boundary between northward-flowing Circumpolar Deep Water and southwardflowing Pacific Deep Water in both the $\chi$-pod data and finescale estimates. Bottom-intensified mixing is observed along most of the section in the deep SWP basin, especially evident in the $\chi$-pod observations that characterize irreversible mixing and less so from the internal-wave based parameterizations. Notable are regions around the east Pacific Rise between $140^{\circ}$ and $100^{\circ} \mathrm{W}$ that show high dissipation rates and diffusivities values along the sloping bottom bathymetry, consistent with enhanced generation and scattering of internal waves over rough topography (Polzin et al. 1997; Mashayek et al. 2017; Holmes et al. 2018; Callies and Ferrari 2018).

The strain and VKE parameterizations show high dissipation rates in patches at middepths, observed also in undulations of isotherms in the middle of the basin away from topography. Topographic enhancement in dissipation rate is observed in the finescale estimates along the abrupt topography of the east Pacific Rise region east of $155^{\circ} \mathrm{W}$. These patterns also reveal some differences between the finescale and temperature microstructure estimates from $\chi$-pods, which are metrics of slightly different attributes of the flow. First, the overall (median) dissipation rates from the $\chi$-pods (Fig. 7c) in the abyssal ocean below $1{ }^{\circ} \mathrm{C}$ are slightly higher than the finescale estimates (Figs. 7a,b), but have few regions where their means are significantly different based on bootstrap averages (Fig. 6b). Second, the range of dissipation estimates from finescale parameterizations in regions of high dissipation associated with rough topography is larger than estimates from $\chi$-pods, which likely reflects the fact that the $\chi$-based estimates have significantly more degrees of freedom in their averages. While the current analysis cannot completely rule out all possible biases from $\chi$-pod measurements (see Nash et al. 2021, manuscript submitted to J. Atmos. Oceanic Technol.), the possibility of low biases in finescale parameterizations (Klymak et al. 2008; Polzin et al. 1995, 2014; Waterman et al. 2014) in the abyssal ocean cannot be overlooked either. Although CTD $\chi$-pod estimates are not significantly biased relative to direct measurements from shear microstructure (Nash et al. 2021, manuscript submitted to J. Atmos. Oceanic Technol.), a broader evaluation of the differences and biases of the 
patterns of turbulent dissipation and amplitude of the energetics exhibited in the abyssal ocean will be the subject of future work and outside the scope of this study.

Mean diffusivities for the northern SWP basin are derived from estimates of average diffusive heat flux along the P06 section (section 3f, Fig. 6a). The basin mean diffusivity for waters colder than $1^{\circ} \mathrm{C}$ calculated from the unsteady-state heat budget agrees within error estimates with the temperature microstructure estimates ( $\chi$-pod) for all isotherms colder than $1^{\circ} \mathrm{C}$, and with the VKE and Strain parameterization for waters warmer than $0.7^{\circ} \mathrm{C}$ (Fig. 6b). The heat budget, $\chi$-pod and strain parameterized estimates that extend to the bottom show bottom intensified diffusivity values, decreasing exponentially toward the warmer temperature classes. The highest diffusivities from the heat budget are around $4.3 \times 10^{-4} \mathrm{~m}^{2} \mathrm{~s}^{-1}$ from 2009 to 2010 and $3.6 \times 10^{-4} \mathrm{~m}^{2} \mathrm{~s}^{-1}$ for 1992 . The diffusivity estimates from the heat budget fall within $95 \%$ bootstrap confidence intervals of $\chi$-pod as well as the strain and VKE parameterizations. In the lower water column below $0.7^{\circ} \mathrm{C}$, the budget estimates agree with $\chi$-pod, VKE, and the strain parameterization within error for most of the temperature classes.

\section{Discussion and summary}

We have demonstrated that the heat fluxes associated with the abyssal limb of the MOC in the northern SWP basin can be well constrained within uncertainty limits using data from repeated hydrography sections, mooring arrays and Deep Argo floats. This is shown by the broad agreement of inferred vertical diffusive heat flux estimates from an unsteady-state heat budget (i.e., allowing for temporal changes in temperature, volume and heat storage) to direct measurements from the CTD-mounted $\chi$-pods and indirect estimates from finescale parameterizations (Fig. 6). We assess the relative contribution of each term in the heat budget, showing that the heat budget is primarily a balance between the inflow of cold waters from the south and the vertical diffusion of heat from above with a small contribution from the unsteady-state warming term. Of particular importance, direct measurements of terms in the unsteady heat budget [Eq. (8)] allow for evaluation of the assessment of measurement error in each term, a key step as we continue to develop our global deep-ocean observing system.

The hydrographic section (P06) results presented here indicate a steady northward volume transport along the bottom limb of the MOC in the Southwest Pacific (Fig. 4) with the gradual warming and eventual disappearance of the coldest abyssal waters being transported northward since the 1990s (Fig. 8). From four repeat occupations of the P06 section between 1992 and 2017 we estimate that isotherms below $0.65^{\circ} \mathrm{C}$ in the SWP basin have been sinking at an average rate between 10 and $30 \mathrm{~m} \mathrm{yr}^{-1}$ within uncertainty bounds, encompassing most of the abyssal ocean below $4500 \mathrm{~m}$ in depth. For instance, between 1992 and 2017 the coldest portion of the SWP basin once consisting of waters colder than $0.6^{\circ} \mathrm{C}$ had warmed to $\sim 0.62^{\circ} \mathrm{C}$, resulting in an average isotherm heave of more than $1000 \mathrm{~m}$ in the deepest portion of the basin over the period (Fig. 8a). The resulting decrease in the volume of the coldest waters flowing into the basin is compensated by an increase in volume transport of warmer bottom waters. As the abyssal ocean is in flux, we show that the unsteady terms in the heat budget calculation are consequential in the heat balance for the isotherms shrinking in volume. We show that the unsteady terms (section 3a) below $0.64^{\circ} \mathrm{C}$ are within a factor of 3 of the steady and diffusion terms [Fig. 5a, Eq. (8)], which result in an increase by factor of 2-5 in the inferred diffusive heat flux and diffusivity estimates from steady-state in the bottom-most isotherms. While the unsteadystate balance regime (primarily below $0.64^{\circ} \mathrm{C}$ ) occupies a small fraction of the range in temperature coordinates (as shown in Fig. 5), it has consequences for large swaths of the abyssal ocean in the SWP below $4000 \mathrm{~m}$ (Fig. 8a). However, these deviations still remain within our overall estimates of uncertainty, as discussed below.

The largest source of known uncertainty in our budget stems from estimates of total meridional transport in and out of the basin. GO-SHIP measurements offer decadal snapshots of the global ocean. However, a large uncertainty of the total annual transport remains due to the unknown temporal variability in the northward meridional transport. We assessed this variability with Deep Argo (in the abyssal plain) and other published findings from moorings (in the DWBC region) in the SWP basin and incorporated them into the range of uncertainty for the calculated vertical diffusive heat fluxes that would arise from variations in the northward heat transport (Fig. 6). The future implementation of a global array of Deep Argo, complemented with the continued GO-SHIP cruises, will allow for broader assessment of the interannual to decadal variability of the deep meridional transport and will greatly reduce the uncertainty spread in the results as well as better constrain the variability in the MOC (Roemmich et al. 2019).

Further, there are several sources of uncertainty associated with the turbulent heat flux estimates presented here. Each method used in our comparison has its own intrinsic uncertainties and limitations. The finescale parameterized estimates are based upon a mathematical framework that assumes that the downscale cascade of energy from larger to smaller spatial scales is driven by nonlinear internal wave-wave interactions and results in turbulent dissipation in the ocean. While some previous studies have pointed to a strong agreement between microstructure and finescale estimates in the open ocean (Polzin et al. 2014; Whalen et al. 2015), others have provided insight into regions where these parameterizations may be biased, possibly due to mixing processes other than the cascade of internal wave energy captured by the current state of finescale parameterizations (Polzin et al. 1995; MacKinnon and Gregg 2003; Klymak et al. 2008; Waterman et al. 2014; Ijichi and Hibiya 2015). The $\chi$-pod measurements are a more direct estimate of mixing because they are based on the small scales of turbulence at which irreversible mixing occurs, and hence include more turbulence-producing phenomenology. However, they can be problematic at extremely low stratification (Nash et al. 2021, manuscript submitted to J. Atmos. Oceanic Technol.) and are instantaneous measurements of turbulent events and hence can be biased when turbulence is (as typical) lognormally distributed (e.g., Whalen 2021). Biases in finescale as well as $\chi$-pod estimates could also be introduced in certain regimes 
dominated by turbulent mixing driven by advective process such as downslope bottom Ekman flows near the DWBC are concerned (e.g., Naveira Garabato et al. 2019; Spingys et al. 2021). Furthermore, all methods shown here are subject to the limitation that they represent one snapshot across the basin and may not reflect either meridional or temporal variability in turbulence, which is known to have significant variability in the deep and abyssal ocean (Polzin et al. 1997; Waterhouse et al. 2014; MacKinnon et al. 2017; Kunze 2017).

Despite these uncertainties, the agreement in averagedprofile magnitude and structure between all direct or indirect estimates of turbulence and inverse heat budget estimates is remarkable. A primary motivation for the global $\chi$-pod program was to provide the first high-resolution maps of turbulence microstructure measurements in the deep ocean. The 75 profiles shown in Fig. 7c span a wide swath of varied bottom topography. The section traverses through a range of regimes that are considered dynamically active sites for turbulent mixing in the abyssal ocean (e.g., Polzin et al. 1997; Ledwell et al. 2000; Waterhouse et al. 2014; Ferrari et al. 2016; Mashayek et al. 2017; Drake et al. 2020) including but not limited to a strong DWBC on the flanks of the TongaKermadec Ridge, abyssal plains, ridges, and seamounts as well the sloping rough topography of the east Pacific Rise. Additionally, the sheer number of profiles likely reduces some of the uncertainty associated with poor sampling of episodic turbulence events (e.g., Whalen 2021), facilitating robust averaged profiles.

Some error could arise from imposing a basinwide average temperature gradient calculated from the WOCE hydrographic climatology to estimate average diffusive heat fluxes for the basin. Meridional spatial inhomogeneity in the temperature gradient in the basin could result in significant spatial variations of estimated diffusive heat fluxes and diffusivities. The temperature gradient regime could be especially different from the mean temperature gradients in regions of abrupt or steep topography where multiple isotherms slump or intersect within a short depth range. Furthermore, the vertical temperature gradient is changing in time due to the disappearance of some of the coldest isotherms in the basin (Fig. 8), resulting in a more thermally uniform abyssal ocean and reduced stratification, which in turn has implications for vertical heat fluxes near the bottom (Zhang et al. 2021).

In this study, we quantified the effect of decadal warming on the heat budget through three unsteady terms (section 3a) and calculated inverse estimates of diffusive heat flux and diffusivity in the northern SWP basin [Eq. (8)]. Although the unsteady terms are important in the resulting heat balance for the coldest isotherms that are rapidly warming (Fig. 5a), the resultant effect on the diffusive heat flux and diffusivity remains in the envelope of uncertainty ensuing from temporal variability in the northward abyssal transport (section 3b). However, we find that high-resolution mixing estimates from CTD- $\chi$-pods and indirect estimates from strain and VKE finescale parameterizations agree to within a factor of 3 for all isotherms below $1^{\circ} \mathrm{C}$ in the abyssal SWP basin adding confidence to our residual estimates of mixing in the basin. However, some previous studies (e.g., Katsumata et al. 2021; Huussen et al. 2012) have also found significant (between factors of 8 and 10) disagreement between large-scale inverse and finescale parameterized estimates of mixing in the Indian Ocean. This was largely attributed to discrepancies in the inverse estimates of the strength of the Indian Ocean MOC, perhaps undersampling of intense mixing events on repeat hydrographic sections that sample a minuscule volume of the ocean or the inadequacy of finescale parameterizations to capture mixing processes other than nonlinear internal wave-wave interactions. Looking to the future, the commitment of sustained global measurements of the deep MOC from Deep Argo, GO-SHIP Repeat Hydrography and moored arrays in DWBCs, coupled with high-resolution global measurements of mixing from instrumentation like the CTD $\chi$-pod, will help to close the uncertainty gap as well as advance our understanding of the mechanisms driving water mass transformation and pathways of overturning in the abyssal ocean.

Acknowledgments. We thank the WOCE, CLIVAR, and GO-SHIP programs for collection of the hydrographic and LADCP data used in this study. CLIVAR and GO-SHIP data were collected and made publicly available by the International Global Ship-based Hydrographic Investigations Program (GO-SHIP; http://www.go-ship.org/) and the national programs that contribute to it. The Argo data used here were collected and made freely available by the International Argo Program and by the national programs that contribute to it (https://argo.ucsd.edu; https://www.ocean-ops.org). The Argo Program is part of the Global Ocean Observing System (https:// doi.org/10.17882/42182). Authors Lele, Purkey, MacKinnon, and Nash were supported by NSF (OCE-2023289). Lele was also supported in part by U.S. GO-SHIP (NSF OCE-1437015) and the NASA FINESST program (Grant 80NSSC20K1609). Author Talley was supported in part by U.S. GO-SHIP (NSF OCE-1437015). Author Whalen was supported by NSF Award OCE-1923558. We thank Jim Moum, June Marion, Mike Neeley-Brown, and Andy Pickering for support of $\chi$-pod instrumentation, data collection and processing, which was funded in part by OCE-1335283. The Deep Argo data were obtained from the Global Ocean Data Assimilation Experiment. The Samoan Passage observations were funded by the National Science Foundation under Grants OCE-1029268 and OCE1029483. We thank Ilker Fer, Jacob Wenegrat, and an anonymous reviewer whose comments greatly benefited the final form of this paper.

Data availability statement. All data used for this article are publicly available. Hydrographic data are available at CCHDO (http://cchdo.ucsd.edu), LADCP data are available through the JAMSTEC (http://www.jamstec.go.jp/iorgc/ ocorp/data/beagle2003/) and University of Hawaii (https:// currents.soest.hawaii.edu/home/data/) websites. The $\chi$-pod data collected on P06 2017 Leg 1 and 2 are available from CCHDO (https://microstructure.ucsd.edu/\#/cruise/320620170703 and https://microstructure.ucsd.edu/\#/cruise/320620170820, respectively). The Deep Argo data were obtained online (https:// www.usgodae.org/argo/argo.html). The Samoan Passage data are available from the authors upon request. 


\section{REFERENCES}

Callies, J., and R. Ferrari, 2018: Dynamics of an abyssal circulation driven by bottom-intensified mixing on slopes. J. Phys. Oceanogr., 48, 1257-1282, https://doi.org/10.1175/JPO-D-170125.1.

Desbruyères, D. G., S. G. Purkey, E. L. McDonagh, G. C. Johnson, and B. A. King, 2016: Deep and abyssal ocean warming from 35 years of repeat hydrography. Geophys. Res. Lett., 43, 35610, https://doi.org/10.1002/2016GL070413.

Drake, H. F., R. Ferrari, and J. Callies, 2020: Abyssal circulation driven by near-boundary mixing: Water mass transformations and interior stratification. J. Phys. Oceanogr., 50, 2203-2226, https://doi.org/10.1175/JPO-D-19-0313.1.

Eriksen, C. C., 1978: Measurements and models of fine structure, internal gravity waves, and wave breaking in the deep ocean. J. Geophys. Res., 83, 2989-3009, https:// doi.org/10.1029/JC083iC06p02989.

Ferrari, R., A. Mashayek, T. J. McDougall, M. Nikurashin, and J.-M. Campin, 2016: Turning ocean mixing upside down. J. Phys. Oceanogr., 46, 2239-2261, https://doi.org/10.1175/ JPO-D-15-0244.1.

Fukasawa, M., H. Freeland, R. Perkin, T. Watanabe, H. Uchida, and A. Nishina, 2004: Bottom water warming in the North Pacific Ocean. Nature, 427, 825-827, https://doi.org/10.1038/ nature 02337.

Ganachaud, A., and C. Wunsch, 2003: Large-scale ocean heat and freshwater transports during the world ocean circulation experiment. J. Climate, 16, 696-705, https://doi.org/10.1175/15200442(2003)016<0696:LSOHAF>2.0.CO;2.

Gargett, A. E., 1990: Do we really know how to scale the turbulent kinetic energy dissipation rate $\epsilon$ due to breaking of oceanic internal waves? J. Geophys. Res., 95, 15 971-15 974, https:// doi.org/10.1029/JC095iC09p15971.

Goto, Y., I. Yasuda, and M. Nagasawa, 2018: Comparison of turbulence intensity from CTD-attached and free-fall microstructure profilers. J. Atmos. Oceanic Technol., 35, 147-162, https://doi.org/10.1175/JTECH-D-17-0069.1.

Gouretski, V., and K. P. Koltermann, 2004: WOCE global hydrographic climatology. Berichte des Bundesamtes für Seeschifffahrt und Hydrographie 35/2004, 52 pp., https://rda.ucar.edu/datasets/ ds285.4/docs/bsh35_re.pdf.

Gregg, M. C., 1989: Scaling turbulent dissipation in the thermocline. J. Geophys. Res., 94, 9686-9698, https://doi.org/10.1029/ JC094iC07p09686.

—, E. D'Asaro, J. Riley, and E. Kunze, 2018: Mixing efficiency in the ocean. Annu. Rev. Mar. Sci., 10, 443-473, https://doi.org/ 10.1146/annurev-marine-121916-063643.

Hernández-Guerra, A., and L. D. Talley, 2016: Meridional overturning transports at $30^{\circ} \mathrm{S}$ in the Indian and Pacific Oceans in 2002-2003 and 2009. Prog. Oceanogr., 146, 89-120, https:// doi.org/10.1016/j.pocean.2016.06.005.

Heywood, K. J., A. C. Naveira Garabato, and D. P. Stevens, 2002: High mixing rates in the abyssal Southern Ocean. Nature, 415, 1011-1014, https://doi.org/10.1038/4151011a.

Hofmann, M., and M. A. Maqueda, 2009: Geothermal heat flux and its influence on the oceanic abyssal circulation and radiocarbon distribution. Geophys. Res. Lett., 36, L03603, https:// doi.org/10.1029/2008GL036078.

Hogg, N., P. Biscaye, R. Gardner, and W. Schmitz, 1982: On the transport and modification of Antarctic Bottom Water in the Vema Channel. J. Mar. Res., 40, 231-263.

Holmes, R. M., C. de Lavergne, and T. J. McDougall, 2018: Ridges, seamounts, troughs, and bowls: Topographic control of the dianeutral circulation in the abyssal ocean. J. Phys. Oceanogr., 48, 861-882, https://doi.org/10.1175/JPO-D-170141.1.

Huussen, T. N., A. C. Naveira-Garabato, H. L. Bryden, and E. L. McDonagh, 2012: Is the deep Indian Ocean MOC sustained by breaking internal waves? J. Geophys. Res., 117, C08024, https://doi.org/10.1029/2012JC008236.

Ijichi, T., and T. Hibiya, 2015: Frequency-based correction of finescale parameterization of turbulent dissipation in the deep ocean. J. Atmos. Oceanic Technol., 32, 1526-1535, https:// doi.org/10.1175/JTECH-D-15-0031.1.

Jackett, D. R., and T. J. McDougall, 1997: A neutral density variable for the world's oceans. J. Phys. Oceanogr., 27, 237-263, https://doi.org/10.1175/1520-0485(1997)027<0237:ANDVFT> 2.0.CO;2.

Johnson, G. C., S. G. Purkey, N. V. Zilberman, and D. Roemmich, 2019: Deep Argo quantifies bottom water warming rates in the Southwest Pacific Basin. Geophys. Res. Lett., 46, 2662-2669, https://doi.org/10.1029/2018GL081685.

Katsumata, K., L. D. Talley, T. A. Capuano, and C. B. Whalen, 2021: Spatial and temporal variability of diapycnal mixing in the Indian Ocean. J. Geophys. Res. Oceans, 126, e2021JC017257, https://doi.org/10.1029/2021JC017257.

Kawano, T., M. Aoyama, T. Joyce, H. Uchida, Y. Takatsuki, and M. Fukasawa, 2006: The latest batch-to-batch difference table of standard seawater and its application to the WOCE onetime sections. J. Oceanogr., 62, 777-792, https://doi.org/10.1007/ s10872-006-0097-8.

Klymak, J. M., R. Pinkel, and L. Rainville, 2008: Direct breaking of the internal tide near topography: Kaena Ridge, Hawaii. J. Phys. Oceanogr., 38, 380-399, https://doi.org/10.1175/ 2007JPO3728.1.

Kouketsu, S., M. Fukasawa, I. Kaneko, T. Kawano, H. Uchida, T. Doi, M. Aoyama, and K. Murakami, 2009: Changes in water properties and transports along $24^{\circ} \mathrm{N}$ in the North Pacific between 1985 and 2005. J. Geophys. Res., 114, C01008, https:// doi.org/10.1029/2008JC004778.

— timated from observation and reanalysis product and their influence on sea level change. J. Geophys. Res., 116, C03012, https://doi.org/10.1029/2010JC006464.

Kunze, E., 2017: Internal-wave-driven mixing: Global geography and budgets. J. Phys. Oceanogr., 47, 1325-1345, https://doi.org/ 10.1175/JPO-D-16-0141.1.

— E. Firing, J. M. Hummon, T. K. Chereskin, and A. M. Thurnherr, 2006: Global abyssal mixing inferred from lowered ADCP shear and CTD strain profiles. J. Phys. Oceanogr., 36, 1553-1576, https://doi.org/10.1175/JPO2926.1.

Ledwell, J. R., E. T. Montgomery, K. L. Polzin, L. C. S. Laurent, R. W. Schmitt, and J. M. Toole, 2000: Evidence for enhanced mixing over rough topography in the abyssal ocean. Nature, 403, 179-182, https://doi.org/10.1038/ 35003164.

Lumpkin, R., and K. Speer, 2007: Global ocean meridional overturning. J. Phys. Oceanogr., 37, 2550-2562, https://doi.org/ 10.1175/JPO3130.1.

MacKinnon, J. A., and M. C. Gregg, 2003: Mixing on the latesummer New England shelf-Solibores, shear, and stratification. J. Phys. Oceanogr., 35, 2408-2424, https://doi.org/10.1175/ JPO2822.1.

—- and Coauthors, 2017: Climate process team on internal wavedriven ocean mixing. Bull. Amer. Meteor. Soc., 98, 2429-2454, https://doi.org/10.1175/BAMS-D-16-0030.1. 
Marshall, J., and K. Speer, 2012: Closure of the meridional overturning circulation through Southern Ocean upwelling. Nat. Geosci., 5, 171-180, https://doi.org/10.1038/ngeo1391.

Mashayek, A., R. Ferrari, S. Merrifield, J. R. Ledwell, L. St Laurent, and A. N. Garabato, 2017: Topographic enhancement of vertical turbulent mixing in the Southern Ocean. Nat. Commun., $\mathbf{8}, 14197$, https://doi.org/10.1038/ncomms14197.

Masuda, S., and Coauthors, 2010: Simulated rapid warming of abyssal North Pacific waters. Science, 329, 319-322, https:// doi.org/10.1126/science.1188703.

Mazloff, M. R., P. Heimbach, and C. Wunsch, 2010: An eddypermitting Southern Ocean state estimate. J. Phys. Oceanogr., 40, 880-899, https://doi.org/10.1175/2009JPO4236.1.

McComas, C. H., and P. Müller, 1981: The dynamic balance of internal waves. J. Phys. Oceanogr., 11, 970-986, https://doi.org/ 10.1175/1520-0485(1981)011<0970:TDBOIW>2.0.CO;2.

Meehl, G. A., and Coauthors, 2006: Climate change projections for the twenty-first century and climate change commitment in the CCSM3. J. Climate, 19, 2597-2616, https://doi.org/10.1175/ JCLI3746.1.

Morris, M. Y., M. M. Hall, L. C. St. Laurent, and N. G. Hogg, 2001: Abyssal mixing in the Brazil Basin. J. Phys. Oceanogr., 31, 3331-3348, https://doi.org/10.1175/1520-0485(2001)031<3331: AMITBB $>2.0 . C O ; 2$.

Moum, J. N., and J. D. Nash, 2009: Mixing measurements on an equatorial ocean mooring. J. Atmos. Oceanic Technol., 26, 317-336, https://doi.org/10.1175/2008JTECHO617.1.

Naveira Garabato, A. C., and Coauthors, 2019: Rapid mixing and exchange of deep-ocean waters in an abyssal boundary current. Proc. Natl. Acad. Sci. USA, 116, 13233-13238, https:// doi.org/10.1073/pnas.1904087116.

Nikurashin, M., and R. Ferrari, 2013: Overturning circulation driven by breaking internal waves in the deep ocean. Geophys. Res. Lett., 40, 3133-3137, https://doi.org/10.1002/grl.50542.

Osborn, T. R., 1980: Estimates of the local rate of vertical diffusion from dissipation measurements. J. Phys. Oceanogr., 10, 83-89, https:// doi.org/10.1175/1520-0485(1980)010<0083:EOTLRO>2.0.CO;2.

—, and C. S. Cox, 1972: Oceanic fine structure. Geophys. Astrophys. Fluid Dyn., 3, 321-345, https://doi.org/10.1080/ 03091927208236085.

Polzin, K. L., J. M. Toole, and R. W. Schmitt, 1995: Finescale parameterizations of turbulent dissipation. J. Phys. Oceanogr., 25, 306-328, https://doi.org/10.1175/1520-0485(1995) 025<0306:FPOTD > 2.0.CO;2.

,,-- J. R. Ledwell, and R. W. Schmitt, 1997: Spatial variability of turbulent mixing in the abyssal ocean. Science, 276, 93-96, https://doi.org/10.1126/science.276.5309.93.

— A. C. Naveira Garabato, T. N. Huussen, B. M. Sloyan, and S. Waterman, 2014: Finescale parameterizations of turbulent dissipation. J. Geophys. Res. Oceans, 119, 1383-1419, https:// doi.org/10.1002/2013JC008979.

Purkey, S. G., and G. C. Johnson, 2010: Warming of global abyssal and deep Southern Ocean waters between the 1990s and 2000s: Contributions to global heat and sea level rise budgets. J. Climate, 23, 6336-6351, https://doi.org/10.1175/2010JCLI3682.1.

— Water between the 1980s and 2000s. J. Climate, 25, 5830-5844, https://doi.org/10.1175/JCLI-D-11-00612.1.

- $\longrightarrow$, L. D. Talley, B. M. Sloyan, S. E. Wijffels, W. Smethie, S. Mecking, and K. Katsumata, 2019: Unabated bottom water warming and freshening in the South Pacific Ocean. J. Geophys. Res. Oceans, 124, 1778-1794, https://doi.org/ 10.1029/2018JC014775.
Reid, J. L., 1997: On the total geostrophic circulation of the Pacific Ocean: Flow patterns, tracers, and transports. Prog. Oceanogr., 39, 263-352, https://doi.org/10.1016/S00796611(97)00012-8.

Roemmich, D., S. Hautala, and D. Rudnick, 1996: Northward abyssal transport through the Samoan passage and adjacent regions. J. Geophys. Res., 101, $14039-14055$, https://doi.org/ 10.1029/96JC00797.

— depth, multi-disciplinary array. Front. Mar. Sci., 6, 439, https:// doi.org/10.3389/fmars.2019.00439.

Rudnick, D. L., 1997: Direct velocity measurements in the Samoan Passage. J. Geophys. Res. Oceans, 102, 3293-3302, https:// doi.org/10.1029/96JC03286.

Sloyan, B. M., S. E. Wijffels, B. Tilbrook, K. Katsumata, A. Murata, and A. M. Macdonald, 2013: Deep ocean changes near the western boundary of the South Pacific Ocean. J. Phys. Oceanogr., 43, 2132-2141, https://doi.org/10.1175/ JPO-D-12-0182.1.

Spingys, C. P., A. C. Naveira Garabato, S. Legg, K. L. Polzin, E. P. Abrahamsen, C. E. Buckingham, A. Forryan, and E. E. Frajka-Williams, 2021: Mixing and transformation in a deep western boundary current: A case study. J. Phys. Oceanogr., 51, 1205-1222, https://doi.org/10.1175/JPO-D20-0132.1.

Talley, L. D., 2013: Closure of the global overturning circulation through the Indian, Pacific, and southern oceans. Oceanography, 26, 80-97, https://doi.org/10.5670/oceanog.2013.07.

Thurnherr, A. M., 2011: Vertical velocity from LADCP data. 2011 IEEE/OES/CWTM 10th Working Conf. on Current, Waves and Turbulence Measurement, Monterey, CA, IEEE, 198-204, https://doi.org/10.1109/CWTM.2011.5759552.

— E. Kunze, J. M. Toole, L. St. Laurent, K. J. Richards, and A. Ruiz-Angulo, 2015: Vertical kinetic energy and turbulent dissipation in the ocean. Geophys. Res. Lett., 42, 7639-7647, https://doi.org/10.1002/2015GL065043.

Voet, G., M. H. Alford, J. B. Girton, G. S. Carter, J. B. Mickett, and J. M. Klymak, 2016: Warming and weakening of the abyssal flow through Samoan Passage. J. Phys. Oceanogr., 46, 23892401, https://doi.org/10.1175/JPO-D-16-0063.1.

Waterhouse, A. F., and Coauthors, 2014: Global patterns of diapycnal mixing from measurements of the turbulent dissipation rate. J. Phys. Oceanogr., 44, 1854-1872, https://doi.org/10.1175/ JPO-D-13-0104.1.

Waterman, S., K. L. Polzin, A. C. Naveira Garabato, K. L. Sheen, and A. Forryan, 2014: Suppression of internal wave breaking in the Antarctic circumpolar current near topography. J. Phys. Oceanogr., 44, 1466-1492, https://doi.org/10.1175/JPO-D-120154.1.

Whalen, C. B., 2021: Best practices for comparing ocean turbulence measurements across spatiotemporal scales. J. Atmos. Oceanic Technol., 38, 837-841, https://doi.org/10.1175/JTECHD-20-0175.1.

_ L. D. Talley, and J. A. MacKinnon, 2012: Spatial and temporal variability of global ocean mixing inferred from Argo profiles. Geophys. Res. Lett., 39, L18612, https://doi.org/ 10.1029/2012GL053196.

_ J. A. MacKinnon, L. D. Talley, and A. F. Waterhouse, 2015: Estimating the mean diapycnal mixing using a finescale strain parameterization. J. Phys. Oceanogr., 45, 1174-1188, https:// doi.org/10.1175/JPO-D-14-0167.1.

Whitehead, J. A., and L. V. Worthington, 1982: The flux and mixing rates of Antarctic bottom water within the North 
Atlantic. J. Geophys. Res., 87, 7903-7924, https://doi.org/ 10.1029/JC087iC10p07903.

Whitworth, T., B. A. Warren, W. D. Nowlin, S. B. Rutz, R. D. Pillsbury, and M. I. Moore, 1999: On the deep western-boundary current in the Southwest Pacific Basin. Prog. Oceanogr., 43, 1-54, https://doi.org/10.1016/S0079-6611(99)00005-1.

Wijffels, S. E., J. M. Toole, and R. Davis, 2001: Revisiting the South Pacific subtropical circulation: A synthesis of
World Ocean Circulation Experiment observations along $32^{\circ}$. J. Geophys. Res., 106, 19481-19513, https://doi.org/10.1029/ 1999JC000118.

Zhang, H. J., C. B. Whalen, N. Kumar, and S. G. Purkey, 2021: Decreased stratification in the abyssal southwest Pacific Basin and implications for the energy budget. Geophys. Res. Lett., 48, e2021GL094322, https://doi.org/10.1029/ 2021 GL094322. 